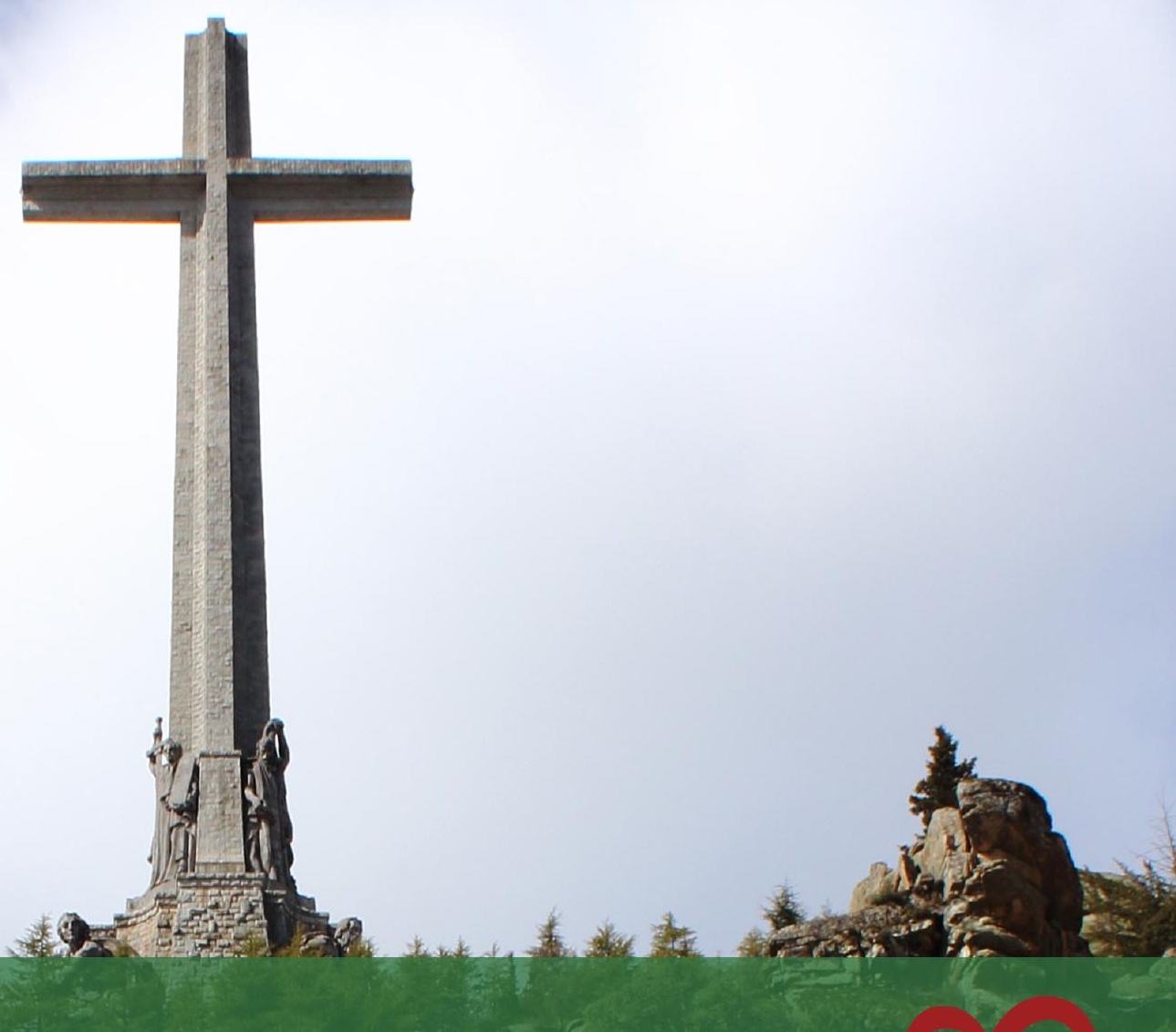

Revista digital de Ciencia y Didáctica de la Historia

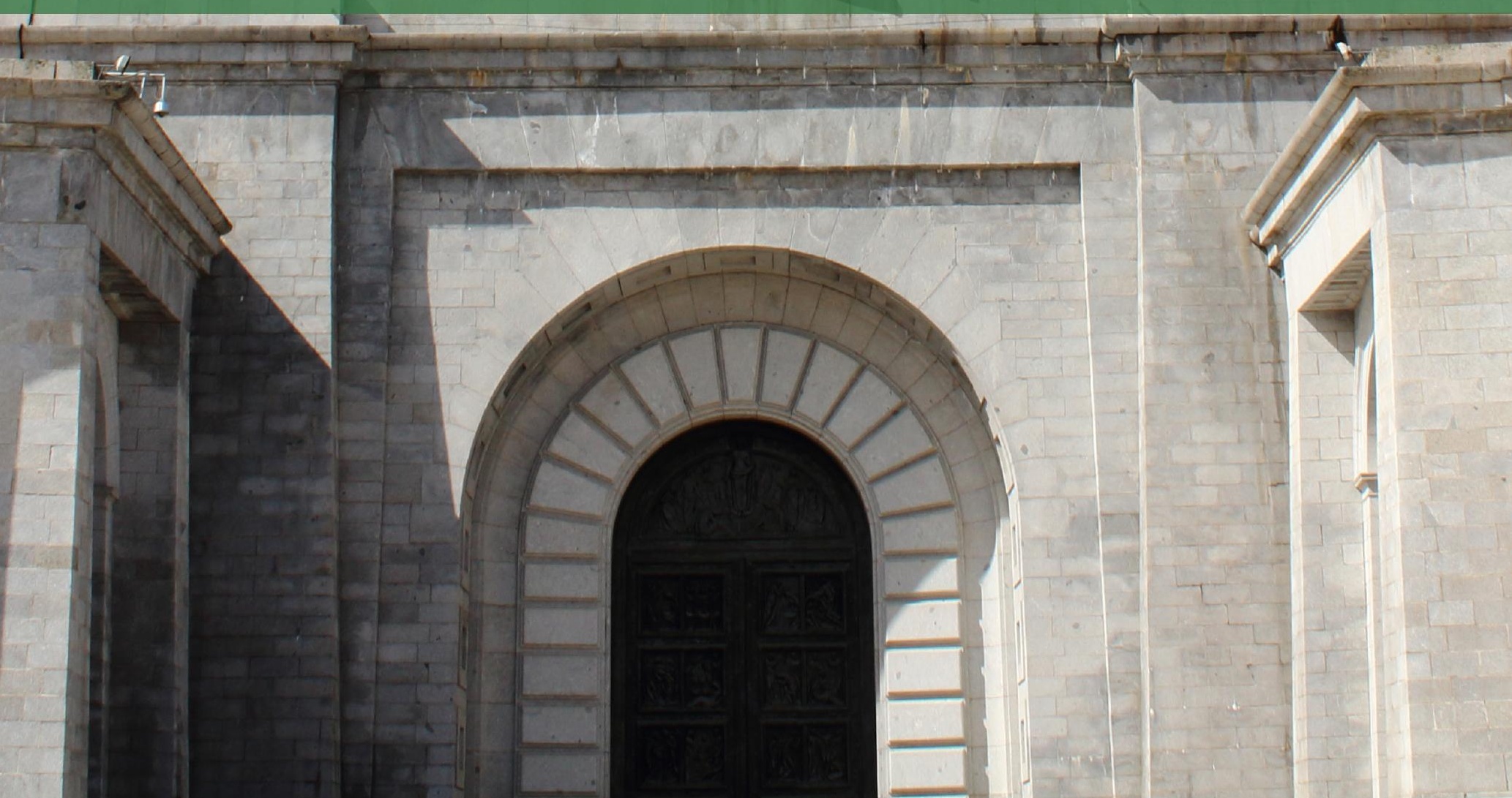




\section{Panta Rei \\ Revista Digital de Ciencia \\ y Didáctica de la Historia}

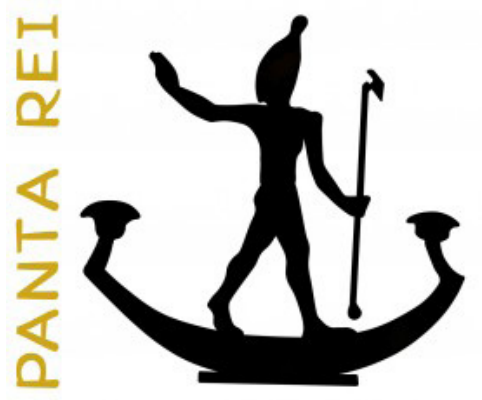

\section{8}

Revista anual

Fecha de inicio: 1995

Revista Panta Rei. pantarei@um.es

Edita:

Centro de Estudios del Próximo Oriente y la Antigüedad Tardía - CEPOAT

Edificio Universitario Saavedra Fajardo.

Universidad de Murcia

C/ Actor Isidoro Máiquez, 9

30007 - MURCIA - ESPAÑA

Teléfono: (+34) 868883890

cepoat@um.es

Web: www.um.es/cepoat/pantarei

Edición 2018

ISSNe: 2386-8864

ISSN: 1136-2464

Depósito legal: MU-966-1995

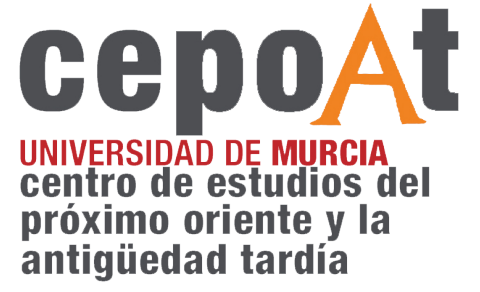

En Portada: Valle de los Caídos, Madrid. (Fotografía de: Adrián Rosell Lucas).

Responsables de los textos: Sus autores.

Responsable de la presente edición: Consejo Editorial Panta Rei. 


\section{CONSEJO DE REDACCIÓN}

\section{Coordinador editorial}

Egea Vivancos, Alejandro

[Didáctica de las Ciencias Sociales, UMU]

\section{Editores}

Botí Hernández, Juan Jesús

[CEPOAT, UMU]

Jiménez Vialás, Helena

[UMU]

López Muñoz, Damaris

[UJA]

Meseguer Gil, Antonio José

[CEPOAT, UNED]

Sáez Giménez, David Omar

[CEPOAT, UMU]

Sánchez Mondéjar, Celso Miguel

[Patrimonio Inteligente]

\section{Secretaria}

Arias Ferrer, Laura

[Didáctica de las Ciencias Sociales, UMU]

\section{Responsable informático}

Martínez García, José Javier

[CEPOAT, UMU]

\section{Traducción y corrección lingüística}

Martínez Martínez, Cristina

[Sociedad Española de Lenguas Modernas]

Albaladejo Albaladejo, Sara

[ISEN, UMU]

\section{CONSEJO ASESOR}

Adroher Auroux, Andrés María [Arqueología, Universidad de Granada]

Albero Muñoz, $\mathrm{M}^{\mathrm{a}}$ del Mar $\left[\mathrm{H} .^{\mathrm{a}}\right.$ del Arte, Universidad de Murcia]

Alia Miranda, Francisco [Historia Contemporánea, UCLM]

Arciniega García, Luis [Historia del Arte, Universidad de Valencia]
Barrio Barrio, Juan Antonio [Historia Medieval, Universidad de Alicante]

Castellano i Solé, Núria [Egiptología, Schola Didàctica Activa S.L.]

Chapman, Arthur [History Education, University College of London, Reino Unido]

Cid López, Rosa María [Historia Antigua, Universidad de Oviedo]

Cobacho López, Ángel [Derecho, Universidad de Murcia]

Cuenca López, José María [Didáctica de las Ciencias Sociales, Universidad de Huelva]

Egea Bruno, Pedro $\mathrm{M}^{\mathrm{a}}$ [Historia Contemporánea, Universidad de Murcia]

Feijoo Martínez, Santiago [Arqueología, Consorcio Ciudad Monumental de Mérida]

García Atienzar, Gabriel [Prehistoria, Universidad de Alicante]

Ginestí Rosell, Anna [Filología Clásica, Katholische Universität Eichstätt-Ingolstadt]

González Monfort, Neus [Didáctica de las Ciencias Sociales, Universidad Autónoma de Barcelona]

González Soutelo, Silvia [Arqueología, Universidad de Vigo]

Haber Uriarte, María [Prehistoria, Universidad de Murcia]

Hernández de la Fuente, David [Historia Antigua, Universidad Complutense]

Hutson, Scott R. [Anthropology, University of Kentucky, EEUU]

Igual Luis, David [Historia Medieval, UCLM]

Irigoyen López, Antonio [Historia Moderna, Universidad de Murcia]

Jover Maestre, Francisco Javier [Prehistoria, Universidad de Alicante]

Mahony, Simon [Digital Humanities, University College of London, Reino Unido]

Marsilla de Pascual, Francisco Reyes [Técnicas historiográficas, Universidad de Murcia]

Martínez-Burgos García, Palma [H. ${ }^{\text {a }}$ del Arte, UCLM]

Mathis, Christian [Didaktik der Geschichte, PH Zürich]

Miralles Maldonado, José Carlos [Filología Clásica, Universidad de Murcia]

Molina Gómez, José Antonio [Historia Antigua, Universidad de Murcia]

Mónica Ghirardi [Historia Moderna, Universidad Nacional de Córdoba, Argentina]

Navarro Espinach, Germán [Historia Medieval, Universidad de Zaragoza]

Noguera Celdrán, José Miguel [Arqueología, Universidad de Murcia]

Ortiz Heras, Manuel [Historia Contemporánea, UCLM]

Panzram, Sabine [Historia Antigua, Universität Hamburg]

Pérez Molina, Miguel Emilio [Filología Clásica, Universidad de Murcia]

Prados Martínez, Fernando [Arqueología, Universidad de Alicante]

Sánchez Ibáñez, Raquel [Didáctica de las Ciencias Sociales, Universidad de Murcia]

Sancho Gómez, Miguel Pablo [Educación, UCAM]

Victoria Moreno, Diego [Historia Contemporánea, UNED]

Vilar García, María José [Historia Contemporánea, Universidad de Murcia]

Vivas Sainz, Inmaculada [H. ${ }^{\text {a }}$ del Arte, UNED]

Zamora López, José Ángel [Próximo Oriente Antiguo, CCHS-CSIC] 

Artículos

El estilo decorativo en las primeras producciones cerámicas en el valle del río Vinalopó (Alicante).

Silvia Martínez Amorós.

Límites históricos del Ateísmo: increencia en la Grecia Antigua.

Ramón Soneira Martínez. .33

Dynamics of Power: an Architectural Reading of the Concentration of Power (Ullastret, 4th-3rd Century BC).

David Jesús Cebrián Martínez.

La mujer como exemplum. Subversión, desafío y resistencia en Valerio Máximo.

Lidia González Estrada.

The narrative framing of violence in teaching resources about the Spanish Conquest of America.

Ángela Bermúdez Vélez y Diego Argumero Martínez.

Modelos de conciencia histórica en el alumnado de Educación Secundaria: tradición, simbología y contextualización en torno a los restos del franquismo.

Diego Miguel-Revilla y María Sánchez Agustí.

La importancia de la contextualización curricular en la enseñanza de la Historia en México.

Enrique Bautista Rojas.

Experiencia didáctica para la enseñanza de la historia contemporánea a través de las fuentes en Educación Superior.

Nayra Llonch-Molina y Verónica Parisi-Moreno 161

\section{Reseñas}

Prados, F., Jiménez, H., Martínez, J.J. (Eds.) (2017). Menorca entre fenicis i púnics / Menorca entre fenicios y púnicos. Murcia: Centro de Estudios del Próximo Oriente y la Antigüedad Tardía de la Universidad de Murcia. 320 págs.

Pete Missingham

Bravo Bosch, M. J. (2017). Mujeres y símbolos en la Roma Republicana. Análisis jurídico-histórico de Lucrecia y Cornelia. Madrid: Dykinson. 333 págs.

Borja Méndez Santiago.

Karp, M. (2016). This Vast Southern Empire: Slaveholders at the Helm of American Foreign Policy. Cambridge: Harvard University Press. 360 pages.

Kevin Caprice.

Livi-Bacci, Massimo (2012). A Short History of Migration. Cambridge: Polity Press. 157 pages.

Alejandro Salamanca Rodríguez. 189

Normas de publicación/Publishing rules 



\title{
La mujer como exemplum. Subversión, desafío y resistencia en Valerio Máximo
}

\author{
Woman as Exemplum. Subversion, Defiance and Resistance in Valerius Maximus
}

González Estrada, Lidia ${ }^{1}$

Universidad de Oviedo

Grupo Deméter

Recibido: 19/02/2018

Aceptado: 01/08/2018

Para citar este artículo: González Estrada, Lidia (2018). La mujer como exemplum. Subversión, desafío y resistencia en Valerio Máximo. Panta Rei. Revista Digital de Ciencia y Didáctica de la Historia, 73-91.

ISSNe: $2386-8864$

DOI: $10.6018 /$ pantarei/2018/4

\section{Resumen}

En el presente texto tratamos de adentrarnos en la complejidad de la acción femenina que, representadas en obras como la de Valerio Máximo, basadas en la ejemplaridad, permite vislumbrar las distintas formas de proceder de las mujeres en la sociedad romana. En los casos que presentamos, no solo podemos ver más allá de los estereotipos, sino que también apreciamos a las mujeres rebelándose contra los roles de género y la moralidad que la sociedad les impone, ya sea como madres, esposas o ciudadanas.

\section{Palabras clave}

Literatura romana, cuestiones de género, rol sexual, estereotipos, familia.

\section{Abstract}

The following article dives into the complexity of women's actions represented in ancient accounts such as Valerius Maximus'. Through the inquiry of these works based on the Roman idea of exempla, it is intended to draw an extensive analysis of women's role in the Roman society. In the studied cases, it is not only possible to see beyond the stereotypes but can also be noted the women's rebellion against gender roles and the morality imposed by the society, either as mothers, wives or citizens.

\section{Keywords}

Roman literature, gender issues, sex role, stereotypes, family.

1 Para contactar con la autora: Lidia González Estrada. Universidad de Oviedo. gonzalezelidia@uniovi.es. 


\section{Introducción}

A propósito de la ejemplaridad femenina en Roma, pretendemos centrarnos principalmente en la obra de Valerio Máximo. Sin embargo, no hemos fijado simplemente nuestra atención en los exempla relativos a las mujeres, sino que nuestra voluntad ha sido profundizar en un cierto tipo de mujer, aquella que desafía los roles de género o el orden establecido y muestra un comportamiento subversivo.

Hemos identificado una serie de mujeres que no solo protagonizan actos alejados del ámbito que les es propio, el doméstico, o del modelo tradicional de matrona romana -reflejado perfectamente en la epigrafía: lanifica, casta, pia, frugi, domiseda, univira (Álvarez, 2012)-sino que llegan a desafiar las decisiones de los magistrados, se expresan libremente en público, defienden sus intereses y llevan a cabo actos violentos o de traición. Por tanto, tratamos de superar las simplificación y estilización de género inherente a una obra de las características de las que nos ocupa, apoyada en la ejemplaridad -aunque es una tendencia general de los autores antiguos-, para rastrear cómo las mujeres lograron esquivar las restricciones sociales que constreñían su capacidad de acción y decisión, así como la forma de presentarse en sociedad (Brennan, 2012). El comportamiento de nuestras protagonistas, pese a las deformaciones literarias, nos acerca a la mujer romana real y a las relaciones entre géneros a las que estas se ven sometidas. De hecho, algunos autores ven en tales deformaciones un punto en común entre el exemplum y las imágenes. Consideran el ejemplo como una suerte de regla mnemotécnica que, al igual que una imagen, evoca ciertos acontecimientos de forma rápida y clara (Langlands, 2000). Además, para Torregaray (2002), la asociación entre el arte y la pedagogía político-moral es evidente, siendo ambos recursos para instruir y hacer recordar. Así, podemos considerar el ejemplo una "imagen social", al igual que la iconografía, que busca presentar al público qué es lo que se entiende y se espera tanto de hombres como de mujeres (Oria, 2016).

Nuestra obra, los Facta et dicta memorabilia, se data en la primera mitad del siglo I d.C. y consta de nueve libros divididos en un total de 91 capítulos. En cada uno de estos capítulos, el autor realiza una introducción en la que lleva a cabo una valoración de la virtud a la que hará referencia con los distintos ejemplos y, después, expone los distintos casos divididos en dos secciones: ejemplos romanos y ejemplos extranjeros ${ }^{2}$. Nos hemos ocupado de ambos, pues, en nuestra opinión, esto enriquece nuestra visión sobre la representación y la percepción de la mujer y lo femenino.

Como hemos expuesto, nuestro interés se centra especialmente en esas "libertinas" y "rebeldes", habitualmente descalificadas con fiereza en las fuentes clásicas. Sin embargo, nos ha resultado verdaderamente interesante detectar que Valerio Máximo no siempre censura o condena las acciones de estas mujeres. Algunas de nuestras protagonistas son elogiadas, aunque sus acciones desafían abiertamente los roles de género. Por tanto, nuestro objetivo en las siguientes páginas será presentar los distintos casos en los que encontramos mujeres actuando en dichos términos de resistencia o connivencia y analizar las peculiaridades, características y contexto de cada uno de ellos. Todo ello con el fin de desentrañar por qué los autores, casi exclusivamente varones, así como la sociedad, ha considerado conveniente que tales acciones de rebeldía femenina deban pasar a la posteridad, a la memoria colectiva, como positivas o negativas, perfilando los límites de una moralidad que ha de reflejar la esencia de lo que constituye ser ciudadano o ciudadana de Roma.

Nuestro autor, vinculado con los círculos de poder de su época, tiene una conexión directa con las tentativas de reforma ideológica y moral de Tiberio (Montero, 2004), que han de entenderse teniendo en cuenta tanto la etapa de Augusto, como el periodo final de la República. Así, para llevar a cabo la transmisión del mensaje moral que interesa al Estado, Valerio Máximo, entre otros autores, se apoya en la ejemplaridad ${ }^{3}$, que está sujeta a ciertas características y formas que le son propias.

2 Para profundizar en las cuestiones asociadas a la obra y su autor, consultar: Malaskov (1984), Bloomer, (1992), Skidmore (1996), David (1998a), Langlands (2000), entre otros.

3 Para profundizar en cuestiones relativas a la ejemplaridad: Malaskov (1984), Loutsch (1998), Langlands (2000), Torregaray (2002), Valette-Cagnac (2010), Urban (2011), entre otros. 
En realidad, el exemplum es una acción situada en el pasado cuyo resultado, al que acompaña la relevancia o autoridad de su autor, permite reforzar la exposición de una idea haciéndola más clara y verosímil. Por tanto, podemos considerar que la ejemplaridad actúa como un instrumento de memoria, entendido como un "mecanismo de selección y elección de aspectos, individuales y colectivos, enmarcados en el tiempo y en el espacio que llamamos realidad" (Hidalgo, 2011, p. 198). Esta se construye a partir de dos modelos claros y contrarios entre sí; es decir, el ejemplo y el contra-ejemplo. Podemos considerar el ejemplo como el mecanismo más simple por el que se trata de trasmitir una lección moral. En él, se exponen hechos o dichos que destacan por ajustarse a los valores y normas por los que se rige la sociedad y, por tanto, se busca que el espectador o lector trate de imitar tales ejemplos. Los personajes que los protagonizan, siguiendo un esquema de simplificación, son exaltados y presentados como el compendio de todas las virtudes romanas; es decir, se convierten en personajes tipo. En el caso de las mujeres, el ejemplo paradigmático sería Lucrecia. El contra-ejemplo presenta el mismo objetivo, pero alcanza su fin a través de un mecanismo distinto. Este no encarna las virtudes y valores morales, más bien podemos entender que los perfila "desde fuera". Sus protagonistas llevan a cabo actos tan abyectos que producen el rechazo del público y, por tanto, buscan mostrar cómo no se debe proceder y las consecuencias nefastas que siguen a tales obras. De nuevo, nos encontramos ante personajes tipo, que, en este caso, se encargan de encarnar los peores vicios. Un claro ejemplo de contra-ejemplo femenino es Tulia, una mujer tan perversa que es capaz de arrollar con su carro a su propio padre. Apuntaremos que, según nuestra opinión, las mujeres son víctimas preferentes de este tipo de simplificación, no solo en el contexto de la ejemplaridad, sino a nivel general, pues su condición, sentimientos, etc. son reflejados por una mayoría de autores masculinos que tratan la feminidad "desde fuera" y cuya visión se encuentra condicionada por estereotipos misóginos.

\section{La madre subversiva}

En los distintos exempla encontramos varios casos en los que las mujeres actúan fuera de los límites que definen su papel como madres, llevando a cabo actos violentos o de traición que se alejan radicalmente de lo que se espera de la matrona romana y de las relaciones maternofiliales en la Roma Antigua. Así mismo, nos enfrentamos a ciertos casos cuya veracidad histórica está más comprometida, pero cuya fuerza ideológica nos permite ilustrar qué aspectos morales o inmorales acerca de las mujeres pretende exponer Valerio Máximo.

En primer lugar, encontramos a madres vengadoras. Mujeres que toman la iniciativa contra aquellos que habrían sido los causantes de la muerte de sus hijos, en lugar de esperar sumisas la respuesta de los varones de la familia. En este sentido, mencionaremos los exempla de las reinas Tómiris y Berenice, que se encuentran en el décimo capítulo del libro IX de nuestra obra, cuyo título es, precisamente, Sobre la venganza. Tómiris, reina de los maságetas, pueblo escita, cortó la cabeza de Ciro que había asesinado a su hijo, y posteriormente: "mandó que la introdujeran en un odre lleno de sangre humana, para así reprobar su insaciable sed de sangre y al mismo tiempo vengar a su hijo, asesinado por el propio Ciro" (Val. Max., IX, 10.ext.1). El cercenamiento de la cabeza, así como la manipulación de la misma parece formar parte de la humillación del criminal y quizá, responder con similar brutalidad al agravio sufrido. Según la célebre anécdota narrada por Heródoto, Tómiris habría rechazado a Ciro II el Grande, por lo que este invade su reino y provoca el suicidio de su hijo Espargapises. Ciro moriría en combate y Tómiris cortaría su cabeza (Hdt., I, 214).

Sin embargo, tal escarmiento -que implica la decapitación y profanación de los restos- parece ser recurrente en la relación entre la mujer y la venganza. Podemos encontrar este mismo castigo en la actuación de otra mujer dentro de nuestra obra. Es el caso de Orgiagonte, princesa de los gálatas (Val. Max., VI, 1.ext.2), que habría vengado así su violación. No obstante, es interesante añadir que también se menciona el mismo ensañamiento para un episodio histórico, el que envuelve a Fulvia 
y Cicerón ${ }^{4}$. Por tanto, parece probable que tal tratamiento del cuerpo no solo subraye la humillación del criminal, sino también la ferocidad femenina, ya esté justificada o no para la mentalidad romana.

Algo diferente es el caso de Berenice. Esta se supone la hija de Ptolomeo II Filadelfo y Arsínoe I, cuyo matrimonio con Antíoco II Teos cerró el tratado de paz entre los ptolomeos y los seléucidas (López, Harto y Villalba, 2003). Dicha mujer, llena de cólera por la muerte de su hijo a manos de la primera esposa de su marido, Antíoco II Teos, con la que volvió a casarse tras haberla repudiado, trató de matar al centinela que había llevado a cabo el crimen. Valerio describe la escena de la siguiente manera:

Se subió armada en su carro y persiguió a Ceneo, el centinela del rey que perpetró aquel horrible crimen. Y como no era capaz de alcanzarlo con su lanza, lo derribó de una pedrada, hizo que los caballos pisotearan su cuerpo y luego atravesó las filas enemigas (Val. Max., IX, 10.ext.1).

La imagen de Berenice, en este caso, no es de una mujer sedienta de sangre que lleva a cabo un acto atroz como venganza, más bien se la presenta como un guerrero que acude al campo de batalla. Armada, en carro y portando su lanza se arroja contra las filas enemigas. Es decir, Berenice muestra un espíritu varonil en la lucha contra los asesinos de su hijo. Así, tanto Tómiris como Berenice "son para Valerio modelos de fortaleza pues, lejos de sumirse en el abatimiento derramando lágrimas por la pérdida del hijo deciden vengar personalmente sus muertes mediante actos no exentos de cierta crueldad" (Montero, 2004, p. 50).

Hallamos en Valerio otros dos casos similares. En primer lugar, volvemos a encontrarnos, de nuevo, a una extranjera, una madre de familia de Esmirna. Esta habría asesinado a su esposo y a su hijo, los cuales habían matado a un hijo de esta mujer fruto de un matrimonio anterior. Una vez que el caso se llevó ante la autoridad romana, Dolabela, este decidió remitir la instrucción al areópago, que ante la imposibilidad de resolver el dilema que suponía tratar de hallar justicia, decidieron citar a la acusada y su acusador para que respondieran ante ellos cien años después. Una estratagema para evitar condenar o absolver a esta mujer. El mismo caso es recogido en Gell., XII, 7, probablemente tomado del propio Valerio Máximo; pero Aulo Gelio menciona como gobernador a Cneo Cornelio Dolabela, aunque probablemente se trate de Publio Cornelio Dolabela, procónsul en Asia entre el 66 y el 67 a.C. (Marcos y Domínguez, 2006), lo que nos permitiría datar la anécdota en la primera mitad del siglo I a.C.

El juicio de Valerio Máximo ante esta mujer no es severo, sino más bien de comprensión, como puede deducirse de las siguientes palabras sobre la disyuntiva de Dolabela: "personalmente no se aventuraba ni a perdonar a aquella mujer que había cometido dos crímenes, ni tampoco a castigar a quien había obrado forzada por un dolor más que razonable" (Val. Max. VIII, 1.ambust.2).

Un juicio muy parecido encontramos en el único caso romano que puede incluirse en la línea de los ya mencionados. En este exemplum, el pretor Marco Popilio Lenate se encuentra en la misma situación que Dolabela, pues es incapaz de decidir si debía castigar o absolver a una mujer que había matado a golpes a su madre, después de que esta, movida por el odio que le profesaba a su hija, hubiera envenenado a sus nietos. En este caso, para nuestro autor, el dolor habría nublado el juicio de aquella mujer y, en definitiva, "había vengado un parricidio con otro" (Val. Max., VIII, 1.ambust.1).

Es preciso advertir la diferencia de valoración entre unos casos y otros. Mientras que en los dos primeros el juicio es abiertamente positivo, en los segundos, ni las autoridades ni nuestro autor se atreven a aplaudir o censurar claramente tales acciones, pues implican la violencia y el asesinato contra miembros de la propia familia. Sin embargo, la tendencia hacia la comprensión de la acción femenina de estos exempla, indica que, ante casos similares, el deber de la madre para con sus hijos implica su protección a toda costa y que el dolor de su pérdida puede desencadenar las

4 Para más información sobre la construcción de la imagen de Fulvia y el episodio que protagoniza con Cicerón vid. Cenerini (2012), Cid (2005) o Ige (2003). 
acciones más insólitas en una mujer. Es decir, lo que justifica en todos estos casos, de algún modo, la actuación femenina es la pietas, que según la definición de Saller, es "a natural devotion to family that may come into conflict with, and override, the demands of the legal constructs of authority" (Saller, 1994, p. 110). Aunque nuestro autor hace especial hincapié en esta virtud en el caso de los hijos para con sus padres con varios exempla, la definición abarcaría a todo el grupo familiar. Este impulso, que para Valerio Máximo constituye prima naturae lex, es una fuerza ineludible, que movería irremediablemente a estas mujeres a buscar venganza, a abandonar su papel tradicional de sumisión y adquirir una fortaleza varonil -como se hace más evidente en el caso de Berenice. Así, la pietas lleva a estas mujeres a enfrentarse con las normas establecidas y a ir más allá de la debilidad de su sexo y de la legalidad, como apunta Saller, tanto si estas mujeres son extranjeras como romanas, pues al ser esta un impulso natural, es inherente a la condición humana. Es interesante, además, advertir cómo para Valerio Máximo las mujeres extranjeras no son denostadas ni utilizadas como contraste para subrayar el correcto comportamiento de la matrona romana. Ya Santiago Montero ha apuntado el trato favorable que Valerio Máximo da a las mujeres extranjeras: "sorprende que las diecisiete mujeres extranjeras reciban un tratamiento favorable en dicha obra" (Montero, 2004, p. 45) Para él, de hecho, Valerio Máximo utiliza a la extranjera como modelo de virtud, en contra de las denuncias de depravación femenina de su época5.

Más allá de los casos de "madres vengadoras", encontramos en nuestra obra tres ejemplos de un modelo distinto de madre, altamente subversivo y cuya veracidad histórica es más plausible. Estos conectan con un fenómeno fundamental para entender una de las principales vías de autonomía a las que va accediendo la mujer romana, la disposición y administración de sus fortunas personales. Esta situación se atestigua especialmente a finales de la República, pues como indica Dixon (2014), en esta época tanto el matrimonio cum manu como la tutela mulierum se habían debilitado considerablemente. De hecho, para Dixon, la autonomía económica de las matronas se convierte en un factor clave de su autoridad dentro del grupo familiar.

Sin embargo, a pesar de esta nueva situación, tal y como apunta Cenerini (2012): "Ma è altrettanto vero che anche queste donne, economicamente più emancipate, rimasero sempre sotto il controllo degli uomini: qualsiasi iniziativa volta a sfuggire da questo controllo sarà sempre stigmatizzata dagli storici antichi" (p. 109). Precisamente los casos que nos disponemos a presentar a continuación son ejemplo de lo apuntado por esta autora, pues, aunque las mujeres tratan de disponer y repartir su herencia según su voluntad, sus testamentos serán anulados.

En primer lugar, mencionaremos el de Septicia (Val. Max. VII, 7.4). Esta mujer, según el testimonio de nuestro autor, disgustada con sus hijos y con el fin de humillarlos, se casó con un hombre de avanzada edad, siendo ella misma ya incapaz de engendrar descendencia, y los excluyó de su testamento. Sus hijos, los Trácalos de Ariminum, la actual Rímini, recurrirían ante el emperador Augusto. Este, amparándolos, anularía tanto la última voluntad de esta mujer como el matrimonio, impidiendo a su marido quedarse con la dote. La razón aducida para justificar la ilegalidad del matrimonio no sería otra que el hecho de que este no se habría celebrado con el fin de engendrar hijos. Tal osadía por parte de esta mujer es duramente criticada por Valerio Máximo, que se refiere a ella en los términos que siguen:

Desprecias a quienes has parido, te casas cuando eres ya infértil, trastocas enfurecida el orden de tu testamento y ni te sonrojas después de ceder todo tu patrimonio a aquél bajo cuyo cuerpo ya casi amortajado pusiste el tuyo marchito y decrépito. Así pues, por comportarte de esta manera, un rayo venido del cielo te arrojó hasta los infiernos (Val. Max. VII, 7.4).

5 Un tratamiento similar se encuentra en Tácito, que alaba la actitud de las mujeres germanas hacia sus hijos, pues los amamantan ellas mismas. lo que difiere del comportamiento adoptado por las mujeres de las élites romanas: "Cada madre cría a su hijo a sus pechos y no lo deja en manos de esclavas o nodrizas" (Tac., Germ., 20.2). 
En Septicia, por tanto, encontramos el mejor ejemplo de madre egoísta, pues no solo entra en conflicto con sus hijos por su testamento, sino que su acción va más allá al atreverse a desafiar, incluso, los fundamentos del matrimonio romano. El objetivo fundamental del mismo es traer al mundo a nuevos ciudadanos que perpetúen el nombre y el patrimonio de sus padres, por tanto, "una buena mujer acepta su papel como mera reproductora" (Mosquera, 2000, p. 264) y no pretende una unión que mancilla el honor de su familia, obstaculiza los intereses de sus hijos o simplemente da una "cobertura legal", tal como parece insinuar Valerio Máximo, a relaciones sexuales que la mujer lleva a cabo por puro placer -una vez que ya no es apta para cumplir con su labor fundamental-, algo absolutamente vetado para ella. En la misma línea, podemos citar uno de los epigramas de Marcial en el que el autor acusa de adulterio a una mujer llamada Telesila por acumular impunemente divorcios y matrimonios, pese a la vigencia de la Lex lulia (VI, 7).

Esta valoración negativa, aunque no tan furibunda, se mantiene en el segundo caso que abordaremos en este apartado, relativo al testamento de Ebucia, esposa de Lucio Menenio Agripa, cuya datación segura no es posible realizar a partir del texto de Valerio Máximo. Esta mujer, a pesar de tener dos hijas, Pletonia y Afronia, decide mantener fuera del testamento a la segunda, por la supuesta animadversión que sentía hacia ella. Sin embargo, en esta ocasión, el testamento no fue anulado, pues la perjudicada consideró conveniente no llevarlo ante los tribunales: "Afronia no quiso querellarse con su hermana [...], y consideró que era más apropiado respetar con resignación el testamento de su madre [...], demostrando con esta actitud que era tan poco digna de aquella afrenta" (Val. Max., VII, 8.2).

En este caso, la valoración hacia la madre que, de nuevo, vuelve a fallar a aquellos a quienes debe su razón de ser, sus hijos, es negativa, pues para Valerio Máximo este testamento está plenae furoris (Val. Max., VIII, 8.2). Sin embargo, no llega a demonizarla, de forma contraria a lo que ocurre con el caso de Septicia. En esta ocasión ningún hijo varón, aquel destinado de forma prioritaria a hacerse cargo del patrimonio familiar, se ve afectado; sino que, por el contrario, es una mujer la que queda fuera del testamento de su madre. Y es que, según parece, para la mentalidad romana no sería inconcebible el hecho de apartar a las mujeres de la herencia, si bien no fue una práctica habitual. El ejemplo lo encontramos en la célebre Lex Voconia de mulierum hereditatibus, un plebiscito del tribuno Q. Voconio Saxa, promovido por Catón y aprobado en el 169 a.C., que prohibía "que las mujeres fueran instituidas herederas por quienes, en calidad de ciudadanos romanos, estuvieran inscritos en la primera clase del censo -con una fortuna superior a los cien mil ases-" (Irigoyen, 2012, p. 13). A pesar de ello, es necesario apuntar que esta ley fue burlada ya desde su promulgación con el sistema de los fideicommissa y que, en época imperial, perdería ya toda significación debido al desuso del censo (Castillo, 1988).

De cualquier manera, esta nos pone ante una clara diferenciación entre hombres y mujeres en la preferencia de acceso a la herencia y que parece mantenerse en la mentalidad de Valerio Máximo a juzgar por el diferente tono de la valoración de ambos casos. A esto podemos añadir la distinta reacción de los excluidos en el testamento de su madre, mientras en el primer caso los hijos varones llegan a apelar ante el propio Augusto, Afronia decide permanecer sumisa ante la voluntad de su madre y acatarla en silencio, es decir, sin acudir a los tribunales y exponerse públicamente. La hija obediente, sumisa y resignada constituye en sí misma un ejemplo que nuestro autor alaba, su actuación la hace digna ante la adversidad que debe soportar; en otras palabras, entra dentro del modelo de mujer socialmente aceptado.

Por último, y como un nuevo ejemplo que refuerza nuestra opinión sobre la diferencia entre hombres y mujeres a la hora de tener acceso a la herencia materna, añadiremos el caso de Cornelia, en el que Marco Celio Rufo, célebre amante de Clodia-Lesbia, presta su ayuda a Quinto Pompeyo. En principio, ambos estarían enfrentados, ya que el primero humillaría al segundo en un juicio celebrado con anterioridad. Sin embargo, estando Pompeyo ausente, se dirigirá a Celio Rufo pidiéndole ayuda y rogándole que vele por sus intereses en los tribunales. El motivo vuelve a ser la herencia, sin embargo, en este caso la madre retenía unos bienes recibidos en fideicommissum que habría de ceder a su hijo. De todos modos, a pesar de la oposición materna, finalmente Celio Rufo 
conseguirá "acabar con la impía avaricia de Cornelia" (Val. Max., IV, 2.7).

El caso es interesante no solo por tratarse de una matrona que no cumple con uno de sus deberes fundamentales: cuidar y velar por sus hijos y sus intereses -en la línea de los ejemplos anteriores. En este caso, Cornelia también pone claramente los suyos por encima de los de su hijo, lo que es un gran acto de rebeldía. El acto de esta mujer desafía el modelo de madre que funciona en la sociedad romana, la aparta claramente del ideal de matrona y la convierte en un ser impío. Sin embargo, sus intentos por usurpar unos bienes que no le corresponden, a costa de su propio hijo, son infructuosos. No se podía permitir el éxito de una osadía tal, por lo que finalmente, es derrotada en el juicio.

Altamente significativo es, en los casos expuestos, el hecho de que "en líneas generales el derecho romano no establece que los hijos sean herederos legítimos de la madre, ya que esta sería su cognata más próxima pero no su agnada" (Hidalgo, 2011, p. 214). Una situación que se modificará en el s. Il d.C., época en la que se dará realidad patrimonial al vínculo materno, lo que se atestigua a través de unas leyes de Antonino Pío y Cómodo, con las que quedó establecido el derecho de los hijos a heredar de su progenitora, aunque esta no se encontrase casada en régimen cum manu. Por tanto, el juicio negativo de nuestro autor ante los casos que hemos expuesto se sustenta en una serie de valores morales asociados a la relación maternofilial, pero no en la existencia de una ley que haya sido vulnerada por estas féminas. A pesar de ello, en el caso de Septicia, tal ausencia de cobertura legal para las demandas de sus hijos no impide que su decisión sea revocada. Por último, en el caso de Cornelia, la obligación como fiduciaria también es moral, pues el fideicomiso no tendrá fuerza obligatoria hasta el siglo I d.C., cuando se crea la figura del praetor fideicomissarius. Ya a partir de época de Augusto, si el fraude a la voluntad del disponente se consideraba especialmente reprobable, el fideicomisario tenía la posibilidad de dirigirse ante los pretores, a los que el príncipe permitía interponer, excepcionalmente, su potestas para hacer valer los fideicomisos (Terrazas, 1998). En este caso la acción de Claudia, considerada altamente censurable, es frenada antes de que se desarrollen estos mecanismos de actuación, pues nos encontraríamos en una fecha cercana a mediados del siglo I a.C.

La falta común de todas estas féminas es la ausencia de respeto a la pietas, Aunque en el caso de Cornelia, su actuación también afecta claramente a la fides, base fundamental en la que se sustentaban los fideicommissa. Estas mujeres, que demuestran toda ausencia de devoción ante sus hijos se convierten en impías, por su falta de respeto al vínculo sagrado de la pietas y la antítesis de la buena madre.

Por tanto, en los Facta et dicta podemos encontrar dos tipos de actuación materna subversiva, pero, mientras que en la segunda la justificación es imposible, pues en estos casos las mujeres osan anteponer sus intereses a los de sus hijos; en los primeros casos, el amor de estas mujeres hacia su descendencia justifica que estas sobrepasen los límites del orden establecido, incluso los legales, en favor del sagrado vínculo de la pietas.

\section{El desafío de la esposa}

En la obra de nuestro autor encontramos otros actos que son objeto de severos juicios y que están marcados por la traición y el asesinato por parte de las mujeres hacia sus maridos.

En primer lugar, mencionaremos a dos mujeres acusadas de envenenar a sus esposos, Publicia y Licinia (Val. Max. VI, 3.8), ambas casadas con hombres ilustres. Es este un tema muy recurrente en el imaginario romano, receloso siempre de la mujer y de sus intenciones, para Cid las llamadas envenenadoras son "ejemplos que se repiten en la historia de Roma. El peligro que asolaba la ciudad, manifiesto en muertes inexplicables de dignos responsables de la República, se atribuyó a las malas artes de sus esposas" (Cid, 2010, p. 138). Estas mujeres son consideradas por algunos autores como el reverso de la matrona nutricia modélica (Palacios, 2014). Según relata Valerio Máximo, nuestras protagonistas "envenenaron a sus esposos [...] (y) fueron estranguladas por decisión de sus familiares. Estos hombres severísimos pensaron que, ante un crimen tan 
evidente, no debían esperar el largo plazo de tiempo requerido por un juicio público" (Val. Max. VI, 3.8).

El envenenamiento -veneficium- era un delito que los romanos consideraban típicamente femenino, por lo que encontramos en la historia de Roma grandes procesos públicos contra mujeres acusadas del mismo. El primero de ellos se celebró en el 331 a.C., durante el consulado de M. Claudio Valerio y C. Valerio Potino, cuando algunos personajes importantes murieron en extrañas circunstancias. Supuestamente, una esclava habría delatado a un grupo de mujeres que habrían llevado a cabo dichos envenenamientos contra sus maridos; entre ellas se encontrarían, según los autores, Cornelia y Sergia, dos mujeres patricias. Tales conspiradoras, obligadas a beber las pócimas y brebajes que se habrían encontrado en sus casas, murieron a la vista de todos. Se crearía, además, una comisión para someter a un proceso regular a otras sospechas. El resultado, más de ciento setenta condenadas a muerte ${ }^{6}$.

Este episodio es interpretado por algunos autores, según explica Cantarella, como "un acto de insurrección feminista" (Cantarella,1997, p. 100) llevado a cabo por un grupo de patricias que pretendían, a través de estos medios extremos, conseguir derechos civiles y políticos. Entre ellos encontramos a Bauman, que considera el episodio como un momento de lucha feminista, en el cual las mujeres habrían imitado los modelos de actuación utilizados por los hombres en los conflictos sociales (Bauman, 1992). Sin embargo, coincidimos con la autora italiana en su consideración de que tales términos y conceptos aplicados a Roma constituyen un anacronismo y se basan en hipótesis indemostrables. Otros, como Cenerini (2002) relacionan este episodio con un posible intento de las mujeres de luchar contra las pestilencias que podrían haber asolado la ciudad, dado el tradicional conocimiento femenino sobre hierbas medicinales y la elaboración de fármacos, y que habría sido interpretado como un intento de envenenamiento. A pesar de ello, es interesante apuntar la existencia de cierta tensión entre ambos sexos, marcada por la sospecha y la desconfianza (Cantarella,1997).

En nuestro caso, al igual que en el anterior, descifrar si el proceso de Publicia y Licinia describe una realidad histórica y si verdaderamente perpetraron esos actos es algo que escapa de nuestro alcance. Sin embargo, apunta la existencia de un temor masculino hacia las mujeres y su capacidad de actuación contra los varones, lo que nos resulta muy interesante.

Así mismo, nos permite introducir otro aspecto de la vida de las mujeres en Roma, la justicia familiar. El derecho del padre a matar a su hija, el ius vitae ac necis, asociado a la patria potestas en la Roma antigua, es algo que no se discute actualmente (Cantarella, 1991), así, los actos criminales o deshonrosos de las mujeres se dirimían en sus hogares, a puerta cerrada, y, por tanto, sin ninguna protección o garantía de un juicio justo. También los varones tendrían reconocido este derecho sobre sus esposas desde antiguo, pues, según la tradición, habría sido regulado por Rómulo para dos casos: el haber cometido adulterio y el haber bebido vino. Sin embargo, Pomeroy (1987) apunta que, en general, el poder del pater familias sobrepasa al del marido; ya que, en definitiva, será el padre quien decida si su hija permanecerá bajo su poder o se someterá al de su nuevo esposo, bajo la forma de la conventio in manum.

Así, serán sus parientes masculinos y/o los de su marido, con total probabilidad, los que decidan si puede permitírsele conservar la vida o si, por el contrario, "la obligación social de salvar el honor perdido a causa de (su) reprobable comportamiento" (Cantarella, 1991, p. 21), pesa más que el amor de su familia. En el caso que nos ocupa, el estrangulamiento es el método utilizado para acabar con la vida de las "envenenadoras"; sin embargo, Cantarella (1991) añade que habitualmente las mujeres eran condenadas a morir de hambre en la cárcel doméstica. A pesar de ello el estrangulamiento, según esta autora, era considerado por los romanos como una muerte privilegiada (Cantarella, 1996).

Este no será, sin embargo, el único acto criminal contra un esposo que recogerá Valerio

6 El hecho es recogido por varios autores entre los que se encuentran Liv., VIII, 18 y el propio Valerio Máximo en Val. Max., II, 5.3. 
Máximo. En el libro IX de nuestra obra, en los capítulos décimo tercero y décimo cuarto, encontramos respectivamente a Tebe y a Laódice. La primera era la esposa de Alejandro, tirano de Feras, y la segunda, la esposa de Antíoco II Teos, -a la que ya nos habíamos referido en el episodio de Berenice como su primera mujer. Ambas decidirían matar a sus esposos, la primera, harta de sus constantes infidelidades; la segunda, por su odio y ambición. En este segundo caso, además, la astucia de Laódice se demuestra en la treta urdida para librarse de la acusación, suplantando a su marido por un hombre con el que este guardaba gran parecido (Val. Max., IX, 14.ext.1).

Ambos casos pueden volver a interpretarse como referencias al temor masculino ante las malas artes de sus esposas, su rencor, la posibilidad de que estas escapen de su control. Subyace bajo todos estos casos la idea de la mujer como un peligro para sus maridos. Estas historias, que pretenden exponer hechos supuestamente reales, esconden una intencionalidad retórica, pero responden también a necesidades psicológicas específicas (Parker, 1998). En este caso, reflejan los miedos, conscientes o inconscientes de los maridos hacia sus esposas.

Lo mismo ocurre con el miedo a la traición femenina, como se aprecia en el siguiente ejemplo que se refiere al proscrito Vetio Salaso: "estaba escondido, así que ¿cómo lo diría?: ¿Su mujer lo entregó para que lo mataran, o lo mató ella misma? ¿Acaso es más leve el crimen al que sólo falta la mano que lo consuma?" (Val. Max., IX, 11.7). En este caso, la traición de la esposa, para nuestro autor, se equipara al propio crimen del asesinato y constituye una acción del todo deplorable.

Para Parker, la ansiedad ante estos miedos de los varones hacia las mujeres tiene una respuesta en un subgénero literario que se encuentra dentro ligado a la ejemplaridad en Roma y que ella denomina "tales of loyalty" . En ellos compara el miedo a la traición femenina con el de la traición de los esclavos en el imaginario del varón romano, debido a que ambos forman parte del grupo familiar, pero tienen un origen externo que los hace potencialmente peligrosos. Sin embargo, en estas narraciones esposas y esclavos consiguen superar sus vicios comunes - pereza, traición, asesinato- demostrando que sus amos y esposos merecen la más alta fidelidad, incluso de aquellos que tienden, precisamente, a lo contrario. Así, para Parker "These tales calm the masters' fears, bring them honor, and serve as an ideological weapon” (Parker, 1998, p. 175).

Sin embargo, podemos preguntarnos qué realidad se encuentra bajo estos ejemplos de "tales of horror". Es posible, como apunta Parker, que la desconfianza para con la esposa emane de la procedencia externa al grupo familiar de la misma; pero, también es probable que tenga su origen en la percepción del descontento que ciertas mujeres encuentran dentro del rol de esposas que la sociedad les ha impuesto. De ahí, también, la crítica y el miedo ante la independencia y la iniciativa femenina, que podemos ver reflejada en los autores clásicos, quienes reaccionan ante la mayor libertad y capacidad de acción de las mujeres que se produce en las décadas de fines de la etapa republicana y del siglo I d. $\mathrm{C}^{8}$.

De hecho, el descontento con la institución matrimonial se repite de forma recurrente en la literatura. Las descaradas adúlteras de Juvenal, las impúdicas damas retratadas por Marcial o las caprichosas mujeres "dotadas" de Plauto se presentan como un castigo para sus esposos y la misogamia está ampliamente recogida en las fuentes. La mujer rica, es decir, aquella que posee una gran dote es el centro de la crítica de Plauto. En sus comedias, esta domina a su marido amparada en la protección que le supone su situación económica9; lo que es interpretado por algunos autores

7 En la obra de nuestro autor también encontramos varios ejemplos de "tales of loyalty" (Val. Max, VI, 7.2; VI, 7.3; VIII, 2.3; IV, 6.ext.2: IV, 6.ext.3). Para los dos primeros casos, su categorización es clara, pues el autor recoge los casos bajo el título Sobre la fidelidad de las mujeres para con sus maridos. Es interesante advertir, siguiendo la teoría de Parker, que Valerio Máximo hace seguir este capítulo por el relativo a la lealtad de los esclavos.

8 Para las distintas visiones sobre la posición de la mujer a finales de la República romana vid. Mañas (2003) y Sirago (1983) para aquellos que abogan por la emancipación femenina o el feminismo en Roma y Casamayor (2016), Castresana (1993), Cortés (2005), Cantarella (1997) o Rhor (2016) para posiciones más escépticas al respecto.

9 Algunas comedias en los que se percibe este tratamiento de los personajes por parte de Plauto son Men. 
como la expresión de la ansiedad ante un posible empoderamiento económico de las mujeres (Rei, 1998).

A pesar de ello, la sociedad romana considera el matrimonio un deber cívico, e incluso, la única manera de contener los vicios inherentes a la condición femenina (Cortés, 2005). Es posible, sin embargo, que, pese a que la voz de la crítica hacia el matrimonio que se ha conservado hasta nuestros días sea masculina, en la tensa relación entre géneros que representan los exempla antes mencionados, nos llegue de forma lejana la indignación y la crítica femenina hacia esta realidad. Podemos también considerar la abundancia de menciones de amantes y adulterios a fines de la República e incluso en época de Augusto, que es muy elevada.

Un claro ejemplo lo encontramos en la poesía elegíaca, cuyo ideal de mujer "no es ya el domum seruauit, lanam fecit de la epigrafía funeraria, sino el vivir entre la libertad, la pasión y el lujo" (Marina, 2010, p. 212). La contradicción que esto supone con los ideales de mujer impuestos por el resto de la sociedad ha hecho plantear a los autores si estas heroínas se tratan solo de un constructo poético o si, por el contrario, forman parte de círculos que podrían constituirse como una auténtica contracultura ${ }^{10}$.

\section{La resistencia de la ciudadana}

Las mujeres romanas, como ciudadanas, están moralmente obligadas a contribuir en favor del Estado, de la patria, al igual que los varones. Por tanto, es interesante advertir cómo el sistema debe recurrir a ese sector habitualmente apartado del ambiente público y la participación política y cómo crea mecanismos para garantizar que esto ocurra. Entre estos recursos están los exempla -como transmisores de los valores y garantes de los intereses del Estado.

Sin embargo, las matronas no solo se movilizan para actuar en pro del Estado, estas también son capaces de hacerlo con el fin de defender sus intereses. Uno de los ejemplos más claros es el que nos proporciona nuestro autor a la hora de tratar los acontecimientos asociados a la derogación de la Lex Oppia (Val. Max. IX, 1.3), recogido en el capítulo titulado Sobre el lujo y las bajas pasiones. En este vemos cómo el desafío a las normas establecidas, así como los prejuicios ligados al sexo femenino, conllevan un juicio muy negativo por parte de Valerio Máximo.

Las mujeres -y es preciso matizar, las pertenecientes a las grandes familias de Roma y aquellas que disfrutan de una posición más desahogada-, se organizarán formando un insoliti coetus, que ejerce una importante presión en los círculos de poder y decisión romanos ${ }^{11}$. Como indica Valerio, estas llegan incluso a rodear la casa de los Brutos, que pretendían, siguiendo a Catón, oponerse a la derogación de esta ley frente a los tribunos Marco Fundanio y Lucio Valerio. Este interesante episodio muestra la fuerza que tiene un grupo de mujeres ricas, con una estrecha conexión con el sector masculino a cargo de las grandes decisiones del Estado, para influir en la esfera pública. En definitiva, demuestra que existían pequeñas parcelas de poder que las romanas "supieron administrar con habilidad y destreza" (Cid, 2010, p. 127).

Como es sabido, la lex Oppia consistía en un plebiscito del tribuno Cayo Opio que procuraría regular el lujo mostrado por las mujeres durante la Segunda Guerra Púnica -se encontraría en vigencia entre los años 215 y 195 a.C.-; una etapa de grave crisis para Roma. En este contexto, se consideró necesario controlar tales muestras de riqueza, por lo que se propusieron las siguientes medidas: prohibir la exhibición de vestidos de colores llamativos y los bienes suntuarios de uso femenino -especialmente, el aurum y la púrpura (García, 1993)-, así como el uso del carro tirado

(766-7; 795-7), Asin. (85-87) o Merc. (275 y ss.).

$10 \mathrm{La}$ aplicación del término "contracultura" para describir la vida de las mujeres que describen los poetas elegiacos fue acuñada por Hallett (1973) a la que sigue Marina (2010).

11 Según el Oxford Latin Dictionary, en su edición de Oxford At the Clarendon Press, 1968, coetus,- us, se utiliza para designar un encuentro, unión o reunión, pero también se aplica para designar movimientos sediciosos o intrigas. 
por caballos a menos de una milla de la ciudad, a excepción de que se utilizara con motivo de un sacrificio. El episodio cobrará una gran relevancia, tanto en la propia época como posteriormente y será tratado en diversas obras. Un claro ejemplo de ello es la comedia, pues la abierta participación de las mujeres despertaría la crítica misógina de autores como Plauto (Aul. 498-536, Epid. 22-235 y Poen. 210ss.). Estos describen los acontecimientos del año 195 a.C. como un ejemplo de la pomposidad femenina y como un apoyo a su crítica caricaturesca del gusto por el lujo, propio, según la mentalidad romana, de las mujeres. Sin embargo, la intención de las matronas, interpretada como banal, es perfectamente justificable si tenemos en cuenta que su atuendo era uno de los medios fundamentales a través de los cuales podían demostrar públicamente su estatus y la prosperidad de su familia. En definitiva, estas mujeres están reclamando "la posibilidad de mostrar públicamente su posición privilegiada" (Cid, 2010, p. 148), algo fundamental en una sociedad aristocrática como la romana.

El mismo tipo de discurso es apreciable en la valoración de nuestro autor, para el que la benevolencia que los hombres habrían demostrado en aquella ocasión será el desencadenante de todo tipo de lujos y de ostentación por parte de las mujeres. Es decir, pone las bases de una de las grandes críticas que se dirigen a las féminas en los últimos años de la República. El texto es el siguiente:

Los hombres de aquella época no repararon en qué desembocaría el obstinado afán de aquella insólita camarilla, o hasta qué punto se propasaría aquella osadía que conculcaba las leyes. [...] Si hubiesen podido barruntar la pomposidad que distingue al ánimo femenino, pomposidad a la que se añade cada día alguna cosa nueva todavía más ostentosa, se habrían opuesto desde su misma raíz al lujo que se les avecinaba (Val. Max. IX, 1.3).

Pero en este pasaje advertimos también la sorpresa ante esa "osadía" femenina, que lleva a las matronas a irrumpir en los escenarios masculinos de poder y a utilizar mecanismos de presión y de protesta dentro de tales espacios, algo insólito para la sociedad republicana romana y, sin duda, una de las razones que da tanta relevancia a este episodio. La información que nos aporta Valerio es breve debido a las propias características formales del exemplum; sin embargo, la comparación con la obra de Tito Livio permite profundizar más en el tipo de acción que las mujeres llevan a cabo. Estas ocupan las calles de la ciudad y los accesos al foro y exponían las razones de su lucha frente a los hombres -incluso cónsules y pretores- con el fin de encontrar apoyos. Aunque no llegaron a acceder al foro y se conformaron con cercarlo -por el momento-, vemos cómo las mujeres eran conscientes de los mecanismos y el modo de proceder en política de los hombres, pues estas los reproducen con el fin de obtener apoyos para su causa. De hecho, según Tito Livio el número de mujeres que se manifestaban de esta manera aumentaba día a día, pues acudían continuamente mujeres desde los centros rurales. La indignación ante este comportamiento se percibe claramente en el discurso que Livio pone en boca de Marco Porcio Catón:

Ahora, nuestra libertad, vencida en casa por la insubordinación de la mujer, es machacada y pisoteada incluso aquí en el foro [...]. Y yo en mi fuero interno no llego a establecer si es peor el hecho por sí mismo o por el precedente que sienta. [...] ¿¿Qué manera de comportaros es esta de salir en público a la carrera, invadir las calles e interpelar a los maridos de otras?' [...] cuál es el motivo que ha llevado a las matronas a presentarse en público, [...] faltando poco para que entrasen en el foro e interviniesen en las asambleas. (Liv., XXXIV, 2-3).

Como contestación, el tribuno Lucio Valerio (Liv., XXXIV, 5) trata de justificar la acción pública de las matronas aludiendo a ciertos episodios míticos de la historia de Roma en los que estas también habrían irrumpido en el espacio y en las cuestiones públicas en favor del bien común. Ahora, considera, solo se manifiestan tratando de defender los derechos que le son propios, una vez que las circunstancias excepcionales que inspiraron la promulgación de la ley han desaparecido 
y se vive una etapa de prosperidad. Sin embargo, el discurso solo justifica tal irrupción en unas circunstancias muy específicas. De hecho, su principal argumento se basa en que ceder a la petición de las matronas es conseguir, a través de ciertas concesiones, que su subordinación resultase más agradable, lo que volvería a las mujeres "más obedientes y menos propensas a entrometerse en las decisiones de los hombres" (Cantarella, 1997, p. 122). Por tanto, ninguna de las posiciones enfrentadas en este episodio consideraría moralmente aceptable la irrupción pública de las mujeres, la principal diferencia es que Catón la rechazaría siempre, mientras que Lucio Valerio la considera aceptable en ocasiones excepcionales.

Sin embargo, Valerio Máximo se acerca a la posición más conservadora de Catón. Así, en el siglo I d.C. se observa en nuestro autor un profundo rechazo al comportamiento de las matronas en esta ocasión. Tal posición conservadora no se debe a una pérdida de libertad femenina con respecto al siglo II a.C., pues aún están por llegar varias conquistas en pro de una mayor autonomía de las mujeres. En nuestra opinión, el episodio, fuera del ambiente político de la época, tendió a verse como un ejemplo del gusto por la pomposidad y el lujo femenino -ignorando su intención de defender la manifestación pública de su posición social-, que arrastraría a las mujeres a actos de gran osadía. Una actuación que no puede contar más que con una valoración negativa por parte de Valerio Máximo y de otros autores. Además, tal interpretación, que simplifica la profundidad y el alcance de la actuación de las matronas es una forma de velar sus motivaciones y su forma de actuar en público, que utiliza mecanismos habituales de la práctica política, que llevan a cabo, además, con éxito.

Además, consideramos que tal rechazo no solo responde al hecho en sí mismo y el desafío que este plantea, sino también al precedente que sienta. Este será utilizado como justificación en otras acciones colectivas de las matronas que expondremos a continuación, demostrando el peligro que tales hechos supondrían para el orden patriarcal establecido. A pesar de todo, la efectividad de la estrategia elegida se manifiesta claramente en el éxito de la propuesta de derogación, que se lleva a cabo a través de la lex Valeria Fundania de lege Oppia sumptuaria del 195 a.C. Sin embargo, no pretendemos considerar que tal éxito se debe solo a la acción conjunta de las mujeres, interpretada por algunos autores como propia de "activistas" ${ }^{2}$, dejándose llevar, tal vez, por modernas interpretaciones sociológicas relativas a la historia de la mujer. Este es el caso de Cantarella (1997). Aunque compartimos con la autora la opinión de que la acción de las mujeres no fue secundaria y que estas se habrían manifestado ante el cuerpo ciudadano con una postura determinada y una voluntad autónoma, consideramos que la participación del elemento masculino fue fundamental. Ambos sexos elevan sus voces por la causa, aunque serán las mujeres las principales promotoras y defensoras de la misma.

Estas trataron en todo momento de conseguir apoyos dentro del sector masculino, lo que, sin duda, sería decisivo en el desenlace final. Esto no quiere decir que la presión ejercida por las mujeres fuera una mera comparsa, sino que estas, conscientes de las reglas del juego, no solo trataron de alcanzar el éxito enfrentándose "desde fuera" al sistema, sino abordándolo también "desde dentro". Es innegable, además, que en esta situación son los tribunos los que hablan en representación de las mujeres y quienes llevan a cabo la propuesta de ley.

En esta ocasión no serán las matronas quienes alcen la voz, pero nuestro autor recoge otros episodios en los que las mujeres rompen con uno de los valores fundamentales de la buena

12 Tal denominación deriva de la interpretación del término axitiosae, presente en ciertos fragmentos de la obra de Plauto. Será Varrón quien los interprete posteriormente como sinónimo de "activistas" o "partidistas"; sin embargo, la moderna crítica filológica se decanta por interpretarlas en el sentido de "gastosas" o "estrafalarias". Esta segunda interpretación tiene sentido dentro de unos fragmentos que parecen aludir a la Lex Oppia, para los que Plauto crearía un término con intenciones irónicas o paródicas que hace referencia a uno de los vicios más propiamente femenino para los romanos. Para más información en torno a las cuestiones filológicas vid. García (2004). Sin embargo, Cid (2017) siguiendo la aclaración del profesor Moralejo considera que el término puede referirse a "las que salen fuera". 
matrona: el silencio y utilizan la palabra en el ámbito público, algo atribuido al hombre adulto y estrechamente asociado con la participación política. De ahí proviene, precisamente, el peligro de la expresión femenina, pues, por un lado, puede llevar a las mujeres a irrumpir en actividades ajenas a su condición y, por otro lado, a mancillar este mecanismo de expresión a través de banalidades, chismes y conversaciones vacías. Ya que el silencio femenino es una de las virtudes de la buena matrona, la mendacidad y la verborragia son vistos como vicios propios de la mujer. Por ello, el primero es un comportamiento digno de elogio, pues rompe con las debilidades asociadas con el sexo femenino. Además, se tiende a considerar que la mujer utiliza la palabra para manipular al hombre, escondiendo bajo un discurso hermoso intenciones maliciosas. Esto es advertido por Jimena Palacios que considera que "la representación de las mujeres como portadoras de un mal que escapa al discernimiento inmediato de quien las observa o de quien las escucha, parece tener plena vigencia en el mundo romano" (Palacios, 2014, p. 101).

Por tanto, si no se puede evitar la manifestación pública de una mujer, se prefiere que esta no se lleve a cabo a través de la palabra, sino de los gestos. Este es el caso de Sempronia, hermana de los Graco, que también es recogido por nuestro autor (Val. Max. III, 8.6). Esta se habría negado a besar públicamente a un tal Lucio Equicio, que trataba de hacerse pasar por hijo de Tiberio Graco. Este gesto, solo permitido entre parientes, demostraba el fraude de Equicio y establecía la forma correcta de expresión femenina ante la asamblea, lo que conlleva que tal actitud sea alabada por Valerio Máximo como muestra de fortaleza (ante las presiones del pueblo y los tribunos), así como de reserva y recato (Cantarella, 1997).

No obstante, encontramos otras mujeres que sí utilizan la palabra para expresarse en la asamblea o ante los tribunales. Esta acción, en principio negativa y contraria a las buenas costumbres, no recibe siempre una mala valoración, sino que llega incluso al elogio en ciertos casos, dependiendo de varios factores, como analizaremos seguidamente. Estas se recogen en el apartado Sobre mujeres que se defendieron a sí mismas o defendieron a otras personas, ante los magistrados. Se trata del tercer capítulo del libro VIII y contiene tres casos de gran relevancia para nuestra exposición, el de Mesia de Sentino (Val. Max. VIII, 3.1), el de Caya Afrania (Afrania, Carfania o Carfinia) (Val. Max. VIII, 3.2) y el de Hortensia (Val. Max. VIII, 3.3).Comenzaremos por el último de estos, pues en este identificamos importantes conexiones con los acontecimientos relativos a la derogación de la Lex Oppia. A pesar de que la información aportada por Valerio Máximo es escasa y no da la sensación de que la intervención de Hortensia llevara asociada una protesta multitudinaria de mujeres, al contrastar la información con otras fuentes, especialmente Apiano, se pone de relieve la profundidad del episodio.

La causa del acontecimiento es el oneroso tributo que los miembros del segundo triunvirato (Marco Antonio, Octaviano y Lépido) habían impuesto a las 1400 mujeres más ricas de Roma con el fin de sufragar sus gastos militares. Muchas de ellas, emparentadas con los proscritos del triunvirato, se vieron indefensas ante la falta de un miembro masculino de su familia que hablase en su nombre y decidieron organizarse para defender sus intereses (Höbenreich, 2005). La primera medida a la que recurrieron distaba de constituir un desafío al sistema y se trataba de apelar a las mujeres de los triunviros, para que intercedieran ante sus maridos en su nombre. Esta acción, sin duda, "muestra que las mujeres jugaban un papel político importante a partir de la influencia que ejercían sobre sus esposos" (Guerra, 2005, p. 77). Pese a la buena disposición de las mujeres de los otros triunviros, Fulvia, esposa de Marco Antonio, se niega en redondo a atender las demandas de este grupo. Como respuesta, las mujeres afectadas se dirigieron al Foro, donde Hortensia, situada en la tribuna, pronunciará un célebre discurso. Las conexiones con el episodio del 195 a.C. con claras: un grupo de mujeres ricas se organiza para ejercer presión y conseguir la revocación de una decisión política tomada por el elemento masculino. Sin embargo, mientras que en aquella ocasión ninguna osó tomar la palabra ante los magistrados, en esta, "por primera y única vez, será una de ellas, Hortensia, la que lidere la embajada ${ }^{13}$ y defienda la causa de sus colegas, pero lo

13 Incluso, algunos autores se plantean si en las palabras de Valerio al respecto pueden interpretarse como 
haría en el espacio político masculino por excelencia, en el Foro" (Cid, 2010, p. 144). De hecho, el discurso que Apiano pone en boca de Hortensia constituye un auténtico alegato sobre la percepción de los derechos y deberes de las mujeres romanas para con el Estado, aunque esta percepción sea la de un hombre que reconstruye un discurso "poniéndose en el papel de las mujeres" un siglo después de los acontecimientos. Este presenta un claro mensaje político: sin representación no debe exigirse ninguna contribución (Bauman, 1992):

¿Por qué participaremos de los castigos, nosotras que no participamos en las ofensas? ¿Por qué hemos de pagar tributos nosotras que no tenemos participación en magistraturas, honores, generalatos, ni, en absoluto, en el gobierno de la cosa pública [...]? [...] ¿Cuándo las mujeres han contribuido con tributos? A estas su propia condición natural las exime de ello en toda la humanidad. (App., BC., IV, 5.32-33).

En cualquier caso y aunque no podemos conocer las verdaderas palabras de nuestra oradora, tal desafío, tal actuación insólita impropia de una mujer habría de ser castigada y constituir un exemplum con una valoración negativa en nuestra obra. Sin embargo, las palabras de Hortensia demostraron tener aceptación no solo en el público femenino, sino también en el masculino, pues según Apiano, cuando los triunviros ordenaron a los lictores disolver aquel grupo de mujeres, la multitud allí congregada se lo impidió.

Es importante apuntar, del mismo modo, que la situación familiar de Hortensia, así como, posiblemente, la del resto de las matronas que protagonizan este episodio y que escogen a esta oradora como portavoz, juega un papel fundamental no siempre tenido en cuenta. Será Cid quien advertirá tal importancia $(2015 ; 2017)$. El conocido triángulo amoroso entre Catón, Marcia y Hortensio ${ }^{14}$, el padre de Hortensia, que Plutarco recoge en la biografía del primero de ellos, conecta a Hortensia con esta ilustre familia. Forman parte de ella Servilia -medio hermana de Catón por parte de madre-, el célebre Bruto -hijo de esta última-, Porcia -prima y esposa de Bruto- y Quinto Servilio Cepión -hermano de Servilia y futuro esposo de Hortensia-. Así, nuestra oradora formaría parte de este círculo, enfrentado abiertamente con los triunviros. Incluso sus hermanos morirán junto a los cesaricidas en la batalla de Filipos (42 a.C.) (Cid, 2015). Por tanto, el episodio que autores como Apiano o Valerio Máximo expresan en términos de conflicto económico, encierra realmente un enfrentamiento político, en el que las mujeres de aquellos que habían sufrido las proscripciones de los triunviros, se niegan a contribuir económicamente en la posible aniquilación de sus familiares y allegados.

Finalmente, el asunto se resolvió reduciendo el número de féminas contribuyentes a 400 y gravando también a algunos hombres (App., BC., IV, 5.34). Para Cid (2015), el tono de complicidad de Apiano, así como la insólita inversión de roles del episodio, sin que implique crítica alguna a sus protagonistas, solo es comprensible en la actitud "patriótica" de Hortensia ${ }^{15}$, que se niega a contribuir a luchas intestinas que asolaban la República, lo que se puede extrapolar al discurso de nuestro autor. En este sentido, también podemos añadir que Hortensia y el resto de las matronas, al igual que las madres vengadoras de nuestro primer apartado, están haciendo todo lo que se encuentra en su mano para salvar a sus familiares, llegando incluso a ocupar el Foro y dirigirse al pueblo desde los rostra. Por tanto, dentro de la lógica narrativa de nuestro autor, su acción se dirige a respetar el sagrado vínculo de la pietas y ha de ser, por lo tanto, valorada de forma positiva. De hecho, para Rohr (2016), la iniciativa e intervención política femenina al final de la época republicana tendió a interpretarse de tal forma por los contemporáneos y autores posteriores, tratando así de justificar la

una sugerencia de la existencia de un ordo matronarum (Guerra, 2005).

14 Catón le cedería su esposa, Marcia, a Hortensio. Este último, muy rico y ya de edad avanzada, pretendía aumentar así su descendencia. Sin embargo, este matrimonio no debió durar mucho tiempo pues Marcia, tras enviudar pronto, volvió a casarse con Catón (Plu., Cat. Min., 25.1-13 y 52.5).

15 Sobre la actuación patriótica femenina y la exaltación de las figuras que la representan vid. Hallet (2004). La autora acuña la palabra matriótico para definir tales comportamientos y discursos. 
actuación extra mores de estas mujeres.

Sin embargo, es muy significativo el tono del elogio que Valerio Máximo le dedica a la oradora, pues si lo analizamos con detalle, vemos que el destinatario principal no es Hortensia, sino su padre, Quinto Hortensio, célebre orador que se habría enfrentado a Cicerón en el proceso contra Verres (López et al., 2003): "con una elocuencia calcada de la de su padre, logró que la mayor parte de las cargas impuestas a las mujeres les fueran devueltas. Volvía por tanto Quinto Hortensio a la vida en la persona de su hija" (Val. Max. VIII, 3.3). Por tanto, el responsable en último término del discurso y el éxito de esta mujer era su padre, quien le infundía su verbo y es este el que representa las demandas de un colectivo de mujeres.

En nuestro siguiente caso, el que corresponde a Mesia de Sentino (Val. Max. VIII, 3.1), de nuevo nos encontramos con una valoración positiva, que se resuelve de manera muy parecida la anterior. Podemos situar este acontecimiento a mediados del siglo II a.C. tomando como referencia al magistrado Lucio Ticio, pues "el nombre del pretor -aunque sea difícil precisar quién era exactamente este Lucio- permite ubicar el proceso de Mesia en la primera mitad del siglo II a.C." (Cantarella, 1997, p. 133). En él, nuestra protagonista habría defendido de forma magistral su causa, de la que nuestro autor no nos aporta más información. Es interesante apuntar al respecto que las mujeres podían postular en una causa propia, sin embargo, tal comportamiento se consideraba reprobable desde el punto de vista moral, aunque no lo fuera jurídicamente (Höbenreich, 2005)

De nuevo, el hábil uso de la palabra es justificado bajo la esencia de un espíritu masculino, negando la posibilidad de que el sexo femenino pueda poseer tal destreza. Valerio Máximo lo expresa de la siguiente forma: "por ocultar bajo su cuerpo de mujer el genio propio de un varón, la apodaron la 'Andrógina'” (Val. Max. VIII, 3.1). Y es que el brillante uso de la oratoria, rasgo más característico de la participación política del ciudadano romano, no puede entenderse si no es en términos masculinos. Por tanto, Valerio Máximo, así como otros autores, han de convertir a estas ciudadanas en ciudadanos. Esta transmutación, según nuestra opinión, resuelve a ojos de los romanos la perplejidad que los casos de Hortensia y de Mesia de Sentino podrían suscitar, pues en esencia, la brillante actuación emana de un "espíritu masculino"16.

Muy diferente, sin embargo, es el caso de Caya Afrania (Afrania, Carfania o Carfinia) (Val. Max. VIII, 3.2). En este la valoración no es solo negativa, sino que nuestro autor llega a calificar de 'monstruo' a la protagonista de este exemplum. La razón parece ser la asiduidad con la que esta mujer se presentaba ante los tribunales y se involucraba en diversas causas. Así, según nuestro autor: "revolucionando una y otra vez los tribunales con aquellos ladridos tan inusuales [...], acabó convirtiéndose en un claro ejemplo de maquinación mujeril. [...] A las mujeres de malas costumbres se les asignó el injurioso apodo de 'Gaya Afrania'” (Val. Max. VIII, 3.2).

El episodio se sitúa a mediados del siglo I a.C., siguiendo a Valerio, que hace constar que la muerte de esta mujer se produce en el segundo consulado de César. Por tanto, al contrario de los casos anteriores, cuya brillantez y excepcionalidad permite alabarlos, siempre bajo términos masculinos, Gaya Afrania, que toma por costumbre mostrarse y defenderse ante los tribunales, rompiendo el silencio de la buena mujer es absolutamente denostada; así, parece ser la asiduidad en el uso de la palabra lo que provoca tal diferencia de valoración, pues puede permitirse defender una buena causa en un momento determinado, pero no ocupar continuamente el espacio público, reservado a los hombres. Además, en este caso vemos de nuevo la estrategia de ridiculización del elemento masculino asociado al inapropiado comportamiento de la mujer, pues su esposo es citado como Licinio Bucco, significando este sobrenombre 'estúpido' (Höbenreich, 2005). Pero tal ridiculización, como se puede entrever, es un elemento del discurso asociado a la valoración del ejemplo, pues en el caso de Hortensia, su padre sale favorecido, aunque podríamos pensar que es infinitamente más osado y desafiante para el régimen patriarcal que una mujer intervenga ante los triunviros, que ante los tribunales.

16 Una reflexión sobre la inversión de roles de género y los valores asociados a los mismos en Hemelrijk (2004), que identifica, en ciertos casos, intenciones propagandísticas en su exposición. 
Encontramos otra interesante mención de Caya Afrania o Carfania muy posterior. En ella, parece que esta mujer no solo se representaría a sí misma en múltiples causas, sino que actuaría como abogada. De hecho, según el testimonio de Ulpiano, ella sería la causa de que se prohibiese al sexo femenino ejercer tal profesión: "En este edicto el pretor [...] prohíbe que las mujeres aboguen por otro. [...] Esta prohibición proviene del caso de Carfania, una mujer muy descarada, que, al actuar sin pudor como abogada e importunar al magistrado, dio motivo a este edicto" (Ulp. Dig. 3.1.1.5).

No podemos concluir si es ciertamente la misma mujer o si el testimonio de ambos es cierto; sin embargo, parece claro que permanecía en la memoria de los romanos este comportamiento insólito de una fémina, fuera esta real o no. A pesar de ello, podemos entender que la época en la que se sitúa a nuestra protagonista, finales de la República, casa bien con un periodo en el que las mujeres habían alcanzado nuevos espacios de libertad.

\section{Reflexiones finales}

La lectura atenta de la obra de Valerio Máximo permite vislumbrar, a pesar de su intención claramente moralizante, a las mujeres rebelándose, precisamente, contra las imposiciones sociales que constriñen su capacidad de acción y de expresión. En ella podemos percibir una realidad social compleja, en la que las madres no siempre actúan en favor de sus hijos; en la que se percibe el descontento de las mujeres con su papel de esposas y en la que las ciudadanas participan políticamente, colaboran en la consecución de sus objetivos comunes con los varones o toman la palabra para defender sus intereses. Sin embargo, podemos ahora preguntarnos cómo explicar la inclusión de todos estos casos en un texto de las características de los Facta et dicta memorabilia.

Para Valerio Máximo, el reflejo de la mujer romana y extranjera viene determinado por la tradición, así como por la voluntad de convertir sus actos en lecciones morales o en instrumentos de su exposición narrativa. Esto le lleva a manipular episodios que podrían responder a la realidad histórica o perpetuar aquellas anécdotas cuya veracidad es muy dudosa, pero cuya efectividad ideológica es clara. Si comparamos los casos con una valoración positiva entre sí, podemos darnos cuenta de que estos corresponden a actos que rompen los roles de género y el orden establecido -lo que en principio es negativo-, con fines comunes; como proteger a la familia o al Estado. De hecho, la pietas es, en varios de estos episodios, el valor fundamental sobre el que se apoya la acción transgresora. Algo que no ha de extrañarnos en una obra datada en época de Tiberio, cuya política conecta estrechamente con los intentos de Augusto de revitalización de la moral tradicional y la natalidad -de ahí la exaltación y el reconocimiento del papel de madre (Dixon, 2014) ${ }^{17}$. En otros casos, la inestabilidad que las acciones subversivas puedan suscitar se neutraliza exponiéndola en términos masculinos. Convertir a estas mujeres desafiantes en hombres acaba con el propio desafío y normaliza la acción.

No obstante, otras condiciones deben cumplirse para que tales actos, en principio censurables, se conviertan en positivos. Estos deben ser excepcionales o darse en épocas, convulsas, de anormalidad -por ejemplo, durante las proscripciones del triunvirato- o estar situadas en un lugar y tiempo remoto. Por el contrario, los casos catalogados como negativos atacan a la familia -especialmente a los miembros varones de la misma-, las decisiones de Estado percibidas como justas -es el caso relativo a la Lex Oppia- o utilizan mecanismos que son aceptados excepcionalmente o en caso de necesidad, de forma habitual -como la expresión en público-. En definitiva, su actuación no encuentra justificación al atentar contra la autoridad y el régimen patriarcal.

De este modo, Valerio Máximo, entre otros autores, reinterpreta y modifica los episodios subversivos y desafiantes femeninos de forma que no ataquen el orden establecido, sino que lo refuercen "desde dentro", en forma de exemplum o "desde fuera", a modo de contra-ejemplo, para

17 Vid. Oria, 2015, para la maternidad en el culto imperial y Domínguez, 2010, para la maternidad en el discurso político imperial. 
adaptarse a un esquema claro de lo que ha de ser el correcto comportamiento de los ciudadanos y ciudadanas romanos. Es decir, reduciéndolos a un lenguaje binario que facilite la transmisión de un mensaje moral simple, con unos objetivos claros: la reafirmación del régimen político y social. Un "travail cumulatif engagé et développé par tous les orateurs et rhéteurs qui à coup de manipulations successives avaient fini par transformer le matériau historique en paradigmes moraux [...] pour convaincre ou émouvir leurs interlocuteurs" (David, 1998b, p. 128).

\section{Bibliografía}

Álvarez, N. (2012). Una aproximación a los ideales educativos femeninos en Roma: matrona docta/ puella docta. Káñina, 36(1), 59-71.

Bauman, R. A. (1992). Women and politics in Ancient Rome. Londres: Routledge.

Bloomer, W. M. (1992). Valerius Maximus and the rhetoric of fhe new nobility. Chapel Hill y Londres: University of North Carolina Press.

Brennan, T. C. (2012). Perceptions of women's power in the Late Republic: Terentia, Fulvia and the generation of 63 BCE. En S. L. James y S. Dillon (eds.), A companion to women in the Ancient World (pp. 354-366). Malden-Oxford-West Sussex: Wiley Blackwell

Cantarella, E. (1991). La mujer romana. Santiago de Compostela: Universidad de Santiago de Compostela.

Cantarella, E. (1996). Los suplicios capitales en Grecia y Roma. Orígenes y funciones de la pena de muerte en la Antigüedad clásica. Madrid: Akal.

Cantarella, E. (1997). Pasado próximo. Mujeres romanas de Tácita a Sulpicia. Madrid: Ed. Cátedra.

Casamayor, S (2016). Impudicitia: la transgresión de la virtud sexual femenina en la Roma antigua. En R. Cordeiro y A. Vázquez (eds.), Estudo de Arqueoloxía, Prehistoria e Historia Antiga: achegas dos novos investigadores (pp. 273-287). Santiago de Compostela: Andavira.

Castillo, A. del (1988). Legislación romana y liberación femenina: una relación inconsciente. Lvcentvm, 7-8, 161-170.

Castresana, A. (1993). Catálogo de virtudes femeninas. Madrid: Tecnos.

Cenerini, F. (2002). La donna romana. Bolonia: II Mulino.

Cenerini, F. (2012). Sessualità e Imperium: la trasgressione femminile alla fine dell'età Repubblicana. Lectora, 18, 99-110.

Cid, R. M. (2005). Clodia imaginada por Cicerón. La construcción de la biografía de una libertina. En A. Pedregal y M. González (eds.), Venus sin espejo. Imágenes de mujeres en la Antigüedad clásica y el cristianismo primitivo (pp. 161-184). Oviedo: KRK Ed.

Cid, R. M. (2010). Mujeres y actividades políticas en la República. Las matronas rebeldes y sus antecesoras en la Roma antigua. En A. Domínguez (ed), Mujeres en la Antigüedad Clásica: género, poder y conflicto (pp. 125-152). Madrid: Sílex.

Cid, R. M. (2015). Las silenciosas mujeres de la Roma antigua. Revisiones desde el género y la historia. En A. Domínguez y R. M. Marina (eds.), Género y enseñanza de la historia. Silencios y ausencias en la construcción del pasado (pp. 187-212). Madrid: Sílex.

Cid, R. M. (2017). Las matronas romanas y los agmina mulierum en la Roma antigua. Del matriotismo a la protesta. En C. Martínez y P. Ubric (eds.), Cartografías de género en las ciudades antiguas. Memoria y poder de las mujeres (pp. 207-231). Granada: Universidad de Granada.

Cortés, R. (2005). Indignación satírica contra las mujeres romanas y sus pasiones: la misoginia en Juvenal. En A. Pedregal y M. González (eds.), Venus sin espejo. Imágenes de mujeres en la Antigüedad clásica y el cristianismo primitivo (pp. 139-159). Oviedo: KRK Ed.

David, J.-M. (ed.) (1998a). Valeurs et mémoire à Rome: Valère Maxime ou la vertu recomposée. París: De Boccard.

David, J.-M. (1998b). Valère Maxime et l'Histoire de la République romaine. En J.-M. David (ed.), Valeurs et mémoire à Rome: Valère Maxime ou la vertu recomposée (pp. 119-130). París: De Boccard. 
Dixon, S. (2014). The Roman Mother. Nueva York: Routledge.

Domínguez, A. (2010). La maternidad como base del dicurso político en el Imperio romano. En Cid, R. (ed.), Maternidad/es: representaciones y realidad social. Edades Antigua y Media (pp. 167185). Oviedo: Al-Mudayna.

García, F. (1993). Las críticas misóginas a las matronas por medio de las meretrices en la comedia plautina. Cuadernos de Filología Clásica. Estudios latinos, 4, 39-48.

García, F. (2004). Axitiosae, (Varro. Ling. VII 66): ¿"Activistas", "extravagantes" o "caprichosas"? Sobre los avatares de una interpretación léxica. Emerita, LXXII, 2, 287-300.

Guerra, S. (2005). Autoridad y poder en los discursos de Fulvia y Hortensia. En C. Alfaro y E. Tébar (eds.), Protai Gynaikes: mujeres próximas al poder en la Antigüedad (pp. 71-80). Valencia: Universitat de Valencia. Servei de Publicacions.

Hallet, J. P. (1973). The role of women in Roman elegy: counter-cultural feminism. Arethusa, 6 (1), 103-124.

Hallet, J. P. (2004). Matriotic games? Cornelia, mother of the Gracchi, and the forging of familyoriented political values. En F. McHardy y E. Marshall (eds.), Women's influence on Classical Civilization (pp. 26-39). Londres y Nueva York: Psychology Press.

Hemelrijk, E. A. (2004). Masculinity and feminity in the Laudatio Turiae. CQ, 54 (1), 185-197.

Hidalgo, M. J. (2011). El sofista Apuleyo de Madaura y la memoria: construcción de la imagen de su esposa, Emilia Pudentila, una aristócrata africana. Studia Historica Historia Antigua, 29, 197-221.

Höbenreich, E. (2005). Andróginas y monstruos. Mujeres que hablan en la antigua Roma. Veleia, 22, 173-182.

Ige, S. (2003). Rhetoric and the feminine character: Cicero's portrayal of Sassia, Clodia and Fulvia. Akroterion, 48, 45-57.

Irigoyen, M. P. (2012). La "emancipación" femenina en la Roma antigua y su percepción en algunas fuentes jurídicas y literarias. Sodalitas, 2, 6-20.

Langlands, R. (2000). Gender and exemplarity in Valerius Maximus (Tesis doctoral). Cambridge: Universidad de Cambridge.

López, S., Harto, M. ${ }^{a}$ L. y Villalba, J. (eds.) (2003). Valerio Máximo. Hechos y dichos memorables. Libros VII-IX. Madrid: Gredos.

Loutsch, C. (1998). Procédés rhétoriques de la légitimation des exemples. En J.-M. David (ed.), Valeurs et mémoire à Rome: Valère Maxime ou la vertu recomposée (pp. 27-41). París: De Boccard.

Malaskov, G. (1984). Valerius Maximus and Roman Historiography. A Study of the exempla Tradition. ANRW II, 32 (1), 437-496.

Mañas, M. (2003). Mujer y sociedad en la Roma imperial del siglo I. Norba, 16, 191-207.

Marcos, M. A. y Domínguez, A. (eds.) (2006). Aulo Gelio. Noches áticas II. Libros XI-XX. Salamanca: Universidad de Léon.

Marina, R. M. (2010). Violencia femenina y poder masculino en la elegía amorosa latina: el cado de la Cintia de Propercio. En A. Domínguez (ed), Mujeres en la Antigüedad Clásica: género, poder y conflicto (pp. 211-228). Madrid: Sílex.

Montero, S. (2004). Mujeres extranjeras en la obra de Valerio Máximo. Gerión, 22 (8), 45-56.

Mosquera, M. E. (2000). El concepto de mujer ideal y del matrimonio en las cartas de Plinio el Joven. Gallaecia, 19, 251-268.

Oria, M. (2015). La maternidad protegida. Cultos y ritos públicos y privados en torno a la maternidad en el mundo romano. En E. Ferrer y A. Pereira (coords.) Hijas de Eva. Mujeres y religión en la Antigüedad (pp. 143-162). Sevilla: Universidad de Sevilla.

Oria, M. (2016). Matronas y madres: la creación de una imagen social. En F. Marco, F. Pina, y J. Remesal (eds.), Autorretraros. La creación de la imagen personal en la Antigüedad (pp. 159174). Barcelona: Edicions de la Universitat de Barcelona.

Palacios, J. (2014). Miradas romanas sobre lo femenino: discurso, estereotipos y representación. 
Asparkia: Investigació feminista, 25, 2014, 92-110.

Parker, H. (1998). Loyal slaves and loyal wives. The crisis of the outsider-within and Roman exemplum literature. En S. R. Joshel y S. Murnaghan (eds.), Women and slaves in Greco-Roman culture: Differential equations (pp. 157-169). Londres y Nueva York: Routledge.

Pomeroy, S. B. (1987). Diosas, rameras, esposas y esclavas: mujeres en la antigüedad clásica. Madrid: Akal.

Rei, A. (1998). Villains, wives and slaves in the comedies of Plautus. En S. R. Joshel y S. Murnaghan (eds.), Women and slaves in Greco-Roman culture: Differential equations (pp. 94-111). Londres y Nueva York: Routledge.

Rohr, F. (2016). Matronae nella tarda repubblica: un nuovo profilo al femminile. En F. Cenerini y F. Rohr (ed.), Matronae in domo et in re publica agentes. Spazi e occasini dell'azione femminile nel mondo romano tra tara reppública e primo impero. Atti del Convegno di Venezia, 16-17 ottobre 2014 (pp. 1-22). Trieste: Edizioni Università di Trieste.

Saller, R. P. (1994). Patriarchy, property and death in the Roman family. Cambridge: Cambridge University Press.

Sirago, V. (1983). Femminismo a Roma nel primo impero. Catanzaro: Rubbettino.

Skidmore, C. (1996). Practical ethics for Roman gentlemen: The work of Valerius Maximus. Exeter: University of Exeter Press.

Terrazas, J. D. (1998). Orígenes y cuadro histórico del fideicomiso. Revista Chilena de Derecho, 25 (4), 939-952.

Torregaray, E. (2002). Contribución al estudio de la memoria como instrumento en Historia Antigua. La transmisión de la memoria de los Cornelii Scipiones. Latomus, 61, 295-311.

Urban, D. C. (2011). The use of exempla from Cicero to Pliny the Younger (Tesis doctoral). Filadelfia : Universidad de Pensilvania.

Valette-Cagnac, E. (2010). L'exemplarite dans I'Histoire romaine de Tite-Live. Une question de genre? Écrire l'histoire, 6, 19-26.

\section{Fuentes}

Apiano. Historia romana III. Madrid: Gredos. 1981. [Edición de A. Sancho].

Aulo Gelio. Noches áticas I. Libros I-X. Salamanca: Universidad de Léon. 2006. [Edición de M. A. Marcos y A. Domínguez].Aulo Gelio. Noches áticas II. Libros XI-XX. Salamanca: Universidad de Léon. 2006. [Edición de M. A. Marcos y A. Domínguez].

Heródoto. Historia. Madrid: Gredos. 1992. [Edición de C. Schrader y F. R. Adrados].

Justiniano. Corpus iuris civilis Iustinianei. Osnabrück: Otto Zeller. 1966. [Edición de I. Fehe].

Plutarco. Vidas paralelas. Madrid: Gredos. 2007. [Edición de J. M. Guzmán y O. Martínez García].

Tácito. Agrícola. Germania. Diálogo sobre los oradores. Madrid: Gredos. 1981. [Edición de J. M. Requejo].

Tito Livio. Historia de Roma desde su fundación. Libros VIII-X. Madrid: Gredos. 1990. [Edición de J. A. Villar y J. Solís].

Tito Livio. Historia de Roma desde su fundación. Libros XXXI-XXXV. Madrid: Gredos. 1990. [Edición de J. A. Villar y J. Gil].

Valerio Máximo. Hechos y dichos memorables. Libros I-VI. Madrid: Gredos. 2003. [Edición de S. López, M. ${ }^{a}$ L. Harto y J. Villalba].

Valerio Máximo. Hechos y dichos memorables. Libros VII-IX. Madrid: Gredos. 2003. [Edición de S. López, M. ${ }^{a}$ L. Harto y J. Villalba]. 


\section{Panta Rei}

PANTA REI es una revista digital de investigación orientada a la Historia y otras ciencias afines. Su principal objetivo es la transmisión del conocimiento científico, dando una oportunidad también a los jóvenes investigadores que quieren abrirse camino en el estudio de las ciencias humanas y sociales. Se compone de estudios originales relacionados con la disciplina histórica así como su didáctica y difusión. Las diferentes secciones que componen la revista son: artículos de investigación, entrevistas a profesionales, recensiones de monografías de actualidad y crónicas de congresos o eventos científicos relevantes.

Todos los artículos publicados son objeto de un proceso de revisión a cargo de un mínimo de dos evaluadores, que se consideran expertos en el ámbito temático del artículo propuesto. Nuestro deseo es poder ofrecer unos contenidos rigurosos, de calidad y de interés.

EI CEPOAT (Centro de Estudios del Próximo Oriente y la Antigüedad Tardía de la Universidad de Murcia) es la institución encargada de la coordinación y gestión de la revista, desde donde anualmente se lanzará la convocatoria para aquellos que estén interesados en publicar sus trabajos, siempre relacionados con la Historia, Arqueología, Historia del Arte, Didáctica de las Ciencias Sociales, etc.

PANTA REI is a digital journal focused on History and other sciences related to it. Its main objective is the transmission of scientific knowledge by giving also an opportunity to young researchers who want to make their way in the study of human and social sciences. It is composed by original studies related to History, as well as its didactics and promotion. The different sections of this journal are: research articles, interviews to professionals, recensions on monographs about current issues and reports about congresses or relevant scientific events.

All the articles published are subject to a revision process carried out by a minimum of two reviewers who are considered to be experts in the field of the article proposed. Our wish is to offer rigorous contents with quality and being of interest to the reader.

CEPOAT (Centre of Studies of the Middle East and Late Antiquity of the University of Murcia) is the institution in charge of the coordination and management of this journal. This is the centre from where the call for papers will be launched for all the people interested in publishing their papers, always related to History, Archeology, Art History, Didactics of the Social Sciences, etc. 


\section{Normas de Publicación}

El autor se compromete a enviar trabajos originales, que no se encuentren publicados en otras revistas ni en otros idiomas. Así mismo, el mismo artículo no podrá ser presentado en otras revistas mientras dure el proceso de evaluación.

\section{Envío y presentación de originales}

Los artículos se enviarán exclusivamente a través del correo electrónico a la dirección pantarei@um.es. Los textos serán enviados en formato DOC y las imágenes en formato JPEG o TIFF, y con un tamaño mínimo de 2000 px. Éstas no aparecerán incorporadas en el texto, sino enviadas en archivo aparte y correctamente numeradas según su posición en el texto. Junto al trabajo, se rellenará y enviará un documento aparte en el que se especifiquen los datos del autor siguiendo el modelo disponible en la página Web de la revista.

Para la redacción de los trabajos se tendrá en cuenta el Manual de la American Psychological Association, en su sexta edición. La extensión máxima de los trabajos será de 30 páginas. La tipografía será Arial 11, con interlineado sencillo y sin espacio alguno entre párrafos. El texto deberá ir justificado a ambos márgenes y sin sangría en los primeros párrafos. Los márgenes serán de $2,50 \mathrm{~cm}$. En los casos en los que fuera necesario incorporar notas, éstas irán a pie de página, enumeradas consecutivamente, con tipografía Arial 10, interlineado sencillo y justificadas a ambos márgenes.

Una información más detallada se encuentra disponible en la página http://www.um.es/cepoat/ pantarei.

\section{Proceso de valoración y evaluación}

Una vez recibidos los trabajos, la Revista realizará una primera valoración. Si el trabajo enviado se ajusta a las normas de presentación propuestas, la temática es coincidente con la línea editorial de la revista y posee la calidad científica necesaria, será remitido al consejo asesor para una primera evaluación. Si no es así en este primer paso se puede rechazar directamente los documentos que incumplan claramente la línea editorial.

Será el Consejo Asesor quien indique a la revista la originalidad, relevancia, estructura, redacción, aparato bibliográfico, etc. del trabajo enviado y, para ello, se designará a dos revisores expertos externos que evaluarán cada uno de los trabajos, que pueden formar parte (o no) de este Consejo Asesor. La selección de los revisores se ajustará a la temática y características metodológicas del trabajo. El nombre y filiación de los autores serán eliminados del trabajo para su revisión, así como los revisores actuarán de manera anónima y confidencial.

Los revisores deberán rellenar un informe de evaluación que centrará su atención en aspectos tales como características formales, originalidad y novedad de los trabajos, relevancia de las propuestas y los resultados, calidad metodológica y validez científica.

Una vez terminado el proceso se decidirá la aceptación o no de los mismos y su publicación en el número que sea pertinente, así como las modificaciones susceptibles de ser realizadas para su final publicación. Dicha notificación se enviará únicamente por correo electrónico, en un plazo máximo de seis meses. 


\section{Publishing rules}

The author is committed to submit original papers not having been published in other reviews or in other languages. In this way, it is not allowed for the same paper to be presented in other reviews during the evaluation process.

\section{Submission and presentation of originals}

The articles will be exclusively submitted by email to pantarei@um.es. The texts will be submitted in DOC format and the images in JPEG or TIFF format, and with a minimum size of 2000 px. Images will not be integrated in the text but sent in another file and properly numbered according to their position in the text. Attached to the paper, a document will be filled out and sent where the author's data will be specified following the model available on the website.

The sixth edition of the Manual of the American Psychological Association will be taken into account for the writing of the papers. The length of the papers must not exceed 30 pages. Typography will be Arial 11 , with simple line spacing and no space between paragraphs. The text must be justified on both margins without indentation in the first paragraphs. Margins size will be $2.50 \mathrm{~cm}$. Where it could be necessary the incorporation of notes, they will be at the bottom of the page, consecutively numbered with typography Arial 10, simple line spacing and justified on both margins.

More detailed information is available on the website: http://www.um.es/cepoat/pantarei.

\section{Examination and assessment process}

The Journal will submit the papers to a first examination once received. If the paper follows the presentation guidelines, the subject agrees with the editorial line of this journal, and possess the scientific quality required, it will be sent to the advisory council for a first assessment. If not, the documents which clearly fail to complete the editorial line may be rejected straightaway in this first step.

The Advisory Council will indicate the originality, relevance, structure, writing, bibliography, etc. of the text to the journal; for this purpose, two outside experts will be designated to review the papers; these experts can be (or not) part of this Advisory Council. The selection of the experts will adjust to the subject and methodological characteristics of the paper. Name and affiliation of the author will be eliminated from the text for its review, in this way experts will act anonymously and confidentially.

The experts will fill out an assessment report which will focus on aspects such as formal characteristics, originality and novelty of the papers, relevance and results of the proposal, methodological quality and scientific validity.

Once the process is finished, the acceptance or not of the papers and its publication in the corresponding edition will be decided, as well as the modifications that may be done for its final publication. This notification will be sent by email within 6 months maximum. 


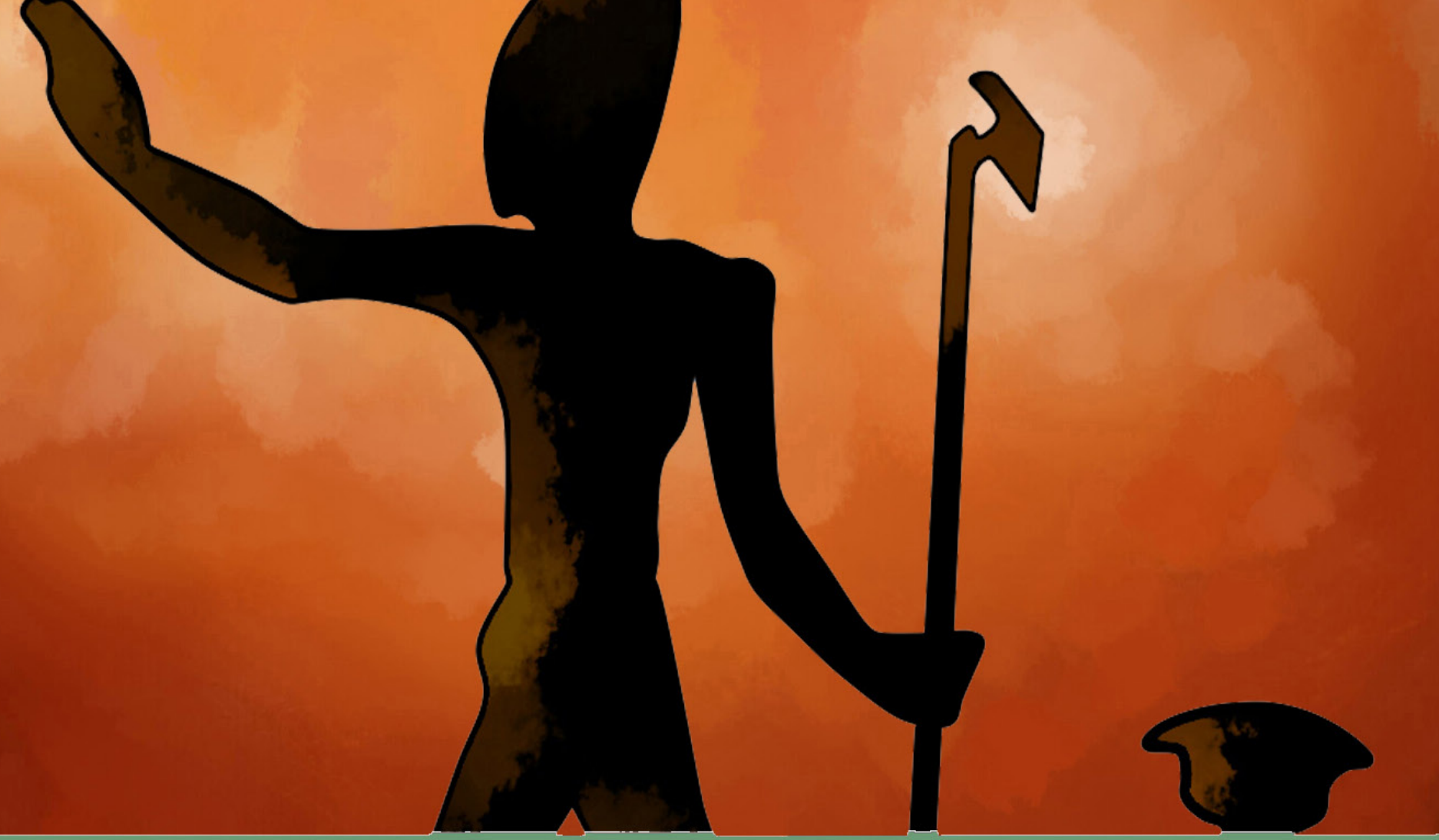

\section{cepot}

UNIVERSIDADD DE MURCIA

centro de estudios del

próximo oriente y la

antigüedad tardía 